\title{
Requirement of AQP4 for Antidepressive Efficiency of Fluoxetine: Implication in Adult Hippocampal Neurogenesis
}

\author{
Hui Kong', ${ }^{1,3}$ Luo-lin Sha',3, Yi Fan', Ming Xiao', Jian-hua Ding', Jie Wu² and Gang Hü,' \\ 'Jiangsu Key Laboratory of Neurodegeneration, Department of Pharmacology, Nanjing Medical University, Nanjing, Jiangsu, PR China; ${ }^{2}$ Division of \\ Neurology, Barrow Neurological Institute, St Joseph's Hospital and Medical Center, Phoenix, AZ, USA
}

\begin{abstract}
Aquaporin-4 (AQP4), a key molecule for maintaining water homeostasis in the central nervous system, is expressed in adult neural stem cells (ANSCs) as well as astrocytes. Neural stem cells give rise to new hippocampal neurons throughout adulthood, and defects in neurogenesis may predispose an individual to depression. Nevertheless, the role of AQP4 in adult hippocampal neurogenesis and chronic mild stress (CMS)-induced depression remains unknown. We herein report that AQP4 knockout disrupted 4-week fluoxetine (I 0 mg/kg per day i.p) treatment-induced enhancement of adult mouse hippocampal neurogenesis as well as behavioral improvement under both basal condition and CMS-evoked depressive state. Meanwhile, AQP4 knockout abolished fluoxetine-induced enhancement of hippocampal cyclic AMP-responsive element binding protein (CREB) phosphorylation. The CMS procedure inhibited hippocampal protein kinase A (PKA) activity, extracellular signal-regulated kinases (ERKI/2), and calcium/calmodulin-dependent protein kinase IV (CaMKIV) phosphorylation in AQP4 ${ }^{+/+}$and AQP4 ${ }^{-1-}$ mice. Fluoxetine treatment could reverse CMS-induced inhibition of PKA activity and ERKI/2 phosphorylation in both genotypes. However, fluoxetine restored CMS-induced inhibition of hippocampal CaMKIV phosphorylation in AQP4 ${ }^{+/+}$mice but failed in AQP4 ${ }^{-1-}$ mice. Notably, CMS procedure significantly increased the hippocampal AQP4 expression, which was reversed by 4-week fluoxetine treatment. Further investigation showed AQP4 knockout inhibited the proliferation of cultured ANSCs and eliminated the pro-proliferative effect of fluoxetine in vitro. Collectively, these findings suggest that AQP4 is required for the antidepressive action of fluoxetine via regulating adult hippocampal neurogenesis.

Neuropsychopharmacology (2009) 34, 1263-1276; doi:I0.1038/npp.2008. I85; published online 15 October 2008
\end{abstract}

Keywords: adult neural stem cells; aquaporin-4; fluoxetine; neurogenesis; depression

\section{INTRODUCTION}

Aquaporins (AQPs) are water channel proteins playing important roles in regulating water homeostasis under physiological and pathological conditions (Verkman, 2005). In total, 13 homologues (AQP0-12) have been identified so far in mammals (Verkman, 2005). AQP4, the predominant isoform in adult brain, is strongly expressed at borders between brain parenchyma and major fluid compartments, including astrocyte foot processes, glia limitans, ependyma, and subependymal cells (Badaut et al, 2002). Astrocytes are the most abundant cell type in the brain contributing to brain homeostasis in several ways, including buffering of extracellular $\mathrm{K}^{+}$, regulating neurotransmitter release, forming the blood-brain barrier (BBB), releasing growth factors, and regulating the brain immune response (Volterra and Meldolesi, 2005). Recent studies demonstrated AQP4

\footnotetext{
*Correspondence: Dr G Hu, Jiangsu Key Laboratory of Neurodegeneration, Department of Pharmacology, Nanjing Medical University, 140 Hanzhong Road, Nanjing, Jiangsu 210029, PR China, Tel: + 8625 86863169, Fax: + 862586863108 , E-mail: ghu@njmu.edu.cn

${ }^{3}$ These authors contributed equally to this work.

Received 4 June 2008; revised 14 September 2008; accepted 15 September 2008
}

knockout altered basal levels of amino-acids neurotransmitters (Fan et al, 2005), downregulated glutamate uptake and glutamate transporter-1 expression in astrocytes (Zeng et al, 2007), slowed cellular $\mathrm{K}^{+}$release and uptake in the brain (Padmawar et al, 2005), and disrupted integrity of the BBB (Zhou et al, 2008). Moreover, AQP4 knockout strongly inhibited formation of glial cell-derived neurotrophic factor in MPTP-treated Parkinson's disease mice (Fan et al, 2008). These findings indicate that AQP4 plays a vital role in modulating astrocytic functions.

It has been demonstrated that impairments of several glial functions (such as glutamate metabolism and deficiency in neurotrophic factors) are likely to contribute to the pathophysiology of depression (Czeh et al, 2006). Postmortem histological analysis of the frontal cortex (Cotter et al, 2001a; Cotter et al, 2001b) and hippocampus (Muller et al, 2001) demonstrated a decreased number of astrocyte in patients suffering from major depression. Moreover, long-term psychosocial stress-induced loss of hippocampal astrocytes was reversed by chronic treatment of antidepressants (Czeh et al, 2006). These findings suggest that astrocytes may contribute to the pathophysiology of depression as well as to the cellular actions of antidepressants. In addition to providing structural, metabolic, and 
tropic support for neurons, astrocytes have been also shown to play much more active roles in adult neurogenesis (Jordan et al, 2007). Previous studies have revealed that astrocytes fill a unique niche composed of different ions, neurotransmitters, hormones, neurotrophic factors, and extracellular substrates for adult neurogenesis in vivo (Bonfanti and Peretto, 2007; Doetsch, 2003; Song et al, 2002). In cultured cell model, the interaction between astrocytes and adult neural stem cells (ANSCs) promoted the generation of new neurons from ANSCs (Lim and Alvarez-Buylla, 1999). These studies suggest that astrocytes within the neurogenic niche are specialized and contribute to the properties of the niche to regulate ANSCs. Thus, AQP4 may participate in adult neurogenesis by regulating astrocytic function. More importantly, AQP4 is the main subtype of AQP in ANSCs (Cavazzin et al, 2006). However, it is unclear whether AQP4 involves adult hippocampal neurogenesis.

Neurogenesis occurs in the adult brain of different species, including rodents, monkeys, and humans, and is particularly important in two regions of the brain, the subgranular zone (SGZ) of dentate gyrus in the hippocampus and the subventricular zone (Ming and Song, 2005). Downregulation of adult hippocampal neurogenesis in response to stress is suggested to contribute to the decreased volume of hippocampus that has been observed in the patients with severe depression (Sheline et al, 2003). Conversely, adult hippocampal neurogenesis is upregulated by chronic antidepressant treatment (Malberg et al, 2000). Now, adult hippocampal neurogenesis has been suggested as a novel theory of depression (Jacobs et al, 2000). Thus, identifying endogenous targets that regulate adult neurogenesis and/or enhance functional neurogenesis will open up new strategies for the treatment of depression (Lie et al, 2004). Fluoxetine, a selective serotonin reuptake inhibitor, produces a rapid increase in extracellular levels of serotonin (5-HT), but its clinical effect usually takes at least 3-4 weeks (Davidson et al, 2002). It has been documented that the therapeutic action of fluoxetine is likely achieved by promoting hippocampal neurogenesis (Santarelli et al, 2003). Our previous studies have demonstrated that AQP4 regulates the serotoninergic neurotransmission in different regions of the adult brain (Fan et al, 2005). Therefore, we presume that AQP4 might participate in the therapeutic effects of fluoxetine.

Chronic mild stress (CMS) is an ethologically relevant animal model of depression, which significantly inhibits adult hippocampal neurogenesis (Alonso et al, 2004). In the present study, AQP4 knockout mice were used to investigate whether AQP4 is involved in fluoxetine-induced enhancement of adult hippocampal neurogenesis under both basal and CMS-induced depressive conditions.

\section{MATERIALS AND METHODS}

\section{Animals and Reagents}

Aquaporin-4 knockout mice were generated by targeted gene disruption as described previously (Fan et al, 2005). These mice have normal growth, development, and survival under physiological conditions except for a mild defect in maximal urinary concentrating ability produced by decreased water permeability in the inner medullary collecting duct, which was the same as that described previously (Ma et al, 1997). Mice were housed with free access to food and water in a room with an ambient temperature of $22 \pm 2{ }^{\circ} \mathrm{C}$ and a $12: 12 \mathrm{~h}$ light/dark cycle. Agematched adult male mice (2-month old) were used to experiments. All experiments were carried out in strict accordance with the National Institutes of Health Guide for the Care and Use of Laboratory Animals.

Fluoxetine (Eli Lilly, Indiana, USA) were prepared in saline, and given at a volume of $10 \mathrm{ml} / \mathrm{kg}$. Control mice were given an isovolume of saline $(10 \mathrm{ml} / \mathrm{kg})$.

\section{Assay of Fluoxetine and Norfluoxetine Level in the Serum and Hippocampus}

See Supplementary Materials and Methods.

\section{Fluoxetine Treatments and CMS Paradigm}

To investigate the role of AQP4 in adult neurogenesis under basal conditions, $\mathrm{AQP} 4^{+/+}$and $\mathrm{AQP} 4^{-1-} \mathrm{CD} 1$ male mice were housed five mice per cage and subjected to daily i.p. injection of fluoxetine $(10 \mathrm{mg} / \mathrm{kg}$; Alonso et al, 2004; El Yacoubi et al, 2003; Grippo et al, 2006) for 4 weeks (Figure 1a).

Chronic mild stress was achieved as described previously (Roy et al, 2007). Both genotypic mice were housed singly. Briefly, the CMS paradigm consists of the sequential application of a variety of mild stressors, including

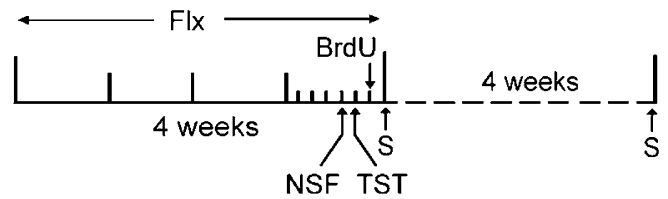

b Depression model

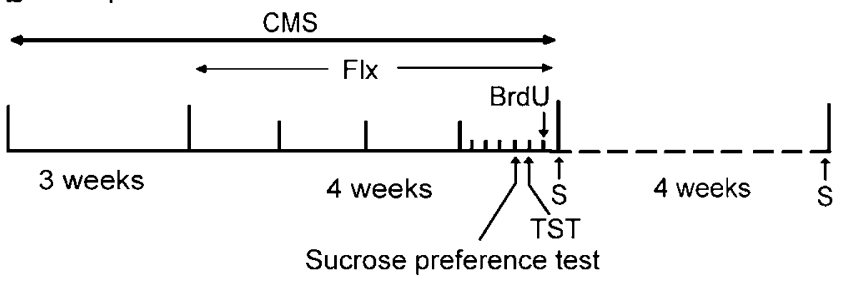

Figure I Schematic representation of the experimental procedure. (a) Fluoxetine ( $10 \mathrm{mg} / \mathrm{kg}$ per day) was once daily administered to normal mice for 4 weeks. For analysis of cell proliferation, mice were received four times injection of bromodeoxyuridine (BrdU) $(4 \times 50 \mathrm{mg} / \mathrm{kg}$, every $2 \mathrm{~h})$ on the last day of the 4-week period. Animals were killed (S) $24 \mathrm{~h}$ after last BrdU administration. To determine the survival and differentiation of newborn cells, mice were killed 4 weeks after the last BrdU administration. (b) Mice were subjected to a variety of chronic mild stressors (CMS) during 3 weeks. Then fluoxetine ( $10 \mathrm{mg} / \mathrm{kg}$ per day) was administered to CMS-treated mice once a day for another 4 weeks. For analysis of cell proliferation, mice received four times injection of BrdU $(4 \times 50 \mathrm{mg} / \mathrm{kg}$, every $2 \mathrm{~h})$ on the last day of the 7-week CMS period. Animals were killed $24 \mathrm{~h}$ after BrdU administration. In the experiments designed to determine the survival and differentiation of newborn cells, mice were killed 4 weeks after the last BrdU administration. 
restraint, inversion of day/night light cycle, soiled cage bedding, $45^{\circ}$ tilted cage, restraint, overnight food and water deprivation, and pairing with another stressed animal, which were introduced over a period of 3 weeks and repeated thereafter. Control mice were handled gently by placing the animal in the palm of the hand every day for $30 \mathrm{~s}$. The physical state was measured weekly over the entire 7-week stress period using a scale from 1 to 3 : a health state was noted 3 and damaged state with piloerection and/or dirty fur was noted 1 . Intermediate state was noted 2 (Alonso et al, 2004). Each measure was scored by an experimenter unaware of the treatment group. In stressed mice, fluoxetine $(10 \mathrm{mg} / \mathrm{kg})$ or vehicle was administered i.p. once a day for 28 days, starting 3 weeks after the beginning of the CMS. Behavioral tests were performed between 0900 and 1200 hours in fourth week of fluoxetine treatment (Figure 1b).

\section{The Novelty-Suppressed Feeding Test}

The novelty-suppressed feeding test (NSF) is designed to assess the anxiolytic effects of chronic antidepressant treatment in rodents (Bodnoff et al, 1988; Santarelli et al, 2003). The testing apparatus consisted of a plastic box that measured $50 \times 50 \times 20 \mathrm{~cm}$. At $24 \mathrm{~h}$ prior to behavioral testing, all food was removed from the rodent's home cage. At the time of testing, a single pellet of mice chow was placed on a white paper platform positioned in the center of the plastic box. Then, a mouse was placed in a corner of the box and a stopwatch was immediately started. The measure of interest (chewing) was scored when the mouse was sitting on its haunches and biting with the use of forepaws.

\section{Sucrose Preference Test}

Mice were given the choice to drink from two bottles for $10 \mathrm{~h}$ (from 09:00 to 19:00 hours) in individual cages; one contained a sucrose solution (1\%) and the other contained only tap water. To prevent possible effects of side preference in drinking behavior, the positions of the bottles in the cage were switched after $5 \mathrm{~h}$. The animals were not deprived of food or water before the test. The consumption of tap water, sucrose solution, and total intake of liquids were estimated simultaneously in the control and experimental groups by weighing the bottles. The preference for sucrose was measured as a percentage of the consumed sucrose solution relative to the total amount of liquid intake (Strekalova et al, 2006).

\section{The Tail Suspension Test}

The tail suspension test (TST) was carried out in mice as described previously (Cryan et al, 2005). Briefly, mice were individually suspended by the distal portion of their tails with adhesive tape for a period of $6 \mathrm{~min}(30 \mathrm{~cm}$ from the floor) in a visually isolated area. The time of immobility of the tail-suspended mice was measured as previously described (Bilkei-Gorzo et al, 2002).

\section{Bromodeoxyuridine Labeling}

On the last day of the 4-week period of fluoxetine treatment, mice were given bromodeoxyuridine (BrdU) intraperitoneally $(4 \times 50 \mathrm{mg} / \mathrm{kg}$ every $2 \mathrm{~h}$; Sairanen et al, 2005). For analysis of cell proliferation, six mice were killed and transcardially perfused $(0.1 \mathrm{M}$ cold phosphate-buffered saline for $5 \mathrm{~min}$ followed by $4 \%$ cold paraformaldehyde) $24 \mathrm{~h}$ after the last BrdU administration. To determine survival and differentiation of BrdU-labeled cells, four mice were killed and perfused 4 weeks after BrdU injection. Other mice were killed by decapitation $3 \mathrm{~h}$ after the last fluoxetine administration and hippocampi were isolated and frozen at $-70^{\circ} \mathrm{C}$.

\section{Immunohistochemical Studies}

After perfusion, brains were postfixed overnight in paraformaldehyde at $4{ }^{\circ} \mathrm{C}$ and stored in $30 \%$ sucrose. Serial sections were then cut $(40 \mu \mathrm{m})$ through each entire hippocampus, using a freezing microtome. Every sixth section was kept for BrdU immunohistochemistry (see Supplementary Materials and Methods for details).

\section{Quantitative Evaluation of Staining}

Bromodeoxyuridine-positive cells were counted using the Optical Fractionator method with Microbrightfield StereoInvestigator software (Stereo Investigator software, Microbrightfield, VT, USA) on a Z-series of sections of $240 \mu \mathrm{M}$ apart. $\mathrm{BrdU}^{+}$counts were limited to the hippocampal granular cell layer and adjacent hilar SGZ margin using an overlay grid of $100 \times 100 \mu \mathrm{m}$.

The volumes of the entire hippocampus (hippocampus proper plus dentate gyrus) were evaluated with the same brain evaluated for the BrdU stain. From rostral to caudal, every sixth section was used to evaluate the hippocampal volume. The $40-\mu \mathrm{m}$-thick sections were stained with $1 \%$ cresyl violet (Nissl staining) to differentiate the regions. Volumes were estimated on the basis of the Cavalieri's principle. The hippocampus was outlined by using the StereoInvestigator software. The computed areas were then summed and multiplied with the thickness of the sections and the intersection distance. Volumes were expressed as $\mathrm{mm}^{3}$.

\section{Western Blot Analysis}

Hippocampi were quickly excised on ice and homogenized $1: 10(\mathrm{w} / \mathrm{v})$ in homogenization buffer (composed of $20 \mathrm{mM}$ Tris-HCl, $150 \mathrm{mM} \mathrm{NaCl}, 1 \mathrm{mM}$ EDTA, $1 \mathrm{mM}$ EGTA, $1 \%$ Triton X-100, $2.5 \mathrm{mM}$ sodium pyrophosphate, $1 \mathrm{mM}$ $\beta$-glycerol phosphate, $1 \mathrm{mM}$ sodium vanadate, and $1 \mu \mathrm{g} / \mathrm{ml}$ leupeptin; pH 7.5) supplemented with a protease inhibitor cocktail (Roche, Mannheim, Germany), followed by centrifugation at $2000 \mathrm{~g}$ for $15 \mathrm{~min}$. Protein lysates were quantified by Bradford assays (Bio-Rad). Western blot analysis was performed by standard protocols using anticyclic AMP-responsive element binding protein (CREB; 1:1000), anti-phospho-CREB (pCREB)-ser133 (1:1000; Cell Signaling Technology, MA, USA), anti-p42/p44 mitogenactivated protein kinases (MAPKs; $1: 2000$ ), anti-activated 
p42/p44 MAPKs (1:2000; Cell Signaling Technology), antiphospho-Thr196 $\alpha$-CaMKIV $(1: 200)$, and anti $\alpha$-CaMKIV (1:200; Santa Cruz Biotechnology, CA, USA) in TBST overnight at $4{ }^{\circ} \mathrm{C}$. The blots were incubated with goat antirabbit or rabbit anti-goat HRP-conjugated secondary antibodies ( $1: 200$; Santa Cruz Biotechnology), and signals were detected by enhanced chemiluminescence western blotting detection reagents (Pierce). The membranes were scanned and analyzed using an Omega 16ic Chemiluminescence Imaging System (Ultra-Lum, CA, USA). The amount of phosphorylated proteins (pCREB, pERK1/2, and pCaMKIV) was normalized on respective total protein (tCREB, tERK1/2, and tCaMKIV) to assess the actual change in the fraction of total protein that was phosphorylated (and thus activated).

\section{Assays of Protein Kinase A and Protein Kinase C Activity}

Protein lysates of hippocampus were also used in protein kinase $\mathrm{A}(\mathrm{PKA})$ and protein kinase $\mathrm{C}(\mathrm{PKC})$ activity assays using radioactive PKA (cat. no. 17-134, Millipore, Billerica, MA, USA) and PKC (cat. no. 17-139, Millipore) assay kits. Protein/sample $(50 \mathrm{mg})$ were used for kinase activity assay following the manufacturer's instructions.

\section{ANSC Culture and $\left[{ }^{3} \mathrm{H}\right]$-Thymidine Incorporation Assay of Cell Proliferation}

See Supplementary Materials and Methods.

\section{Statistics}

All values were expressed as mean \pm SEM. When variances were not homogeneous among groups, rank transformation was used for ANOVA comparison. Results in basal condition were compared by two-way ANOVA (genotype and fluoxetine as factors of variation), followed by independent-samples $t$-tests to analyze the effects of fluoxetine in each group $\left(\mathrm{AQP} 4^{+/+}\right.$and $\left.\mathrm{AQP} 4^{-I-}\right)$. Results in CMS-evoked depressive condition were first compared by two-way ANOVA (genotype and treatment as factors of variation). Then, individual treatment effects in each genotype (AQP4 ${ }^{+/+}$and AQP4 ${ }^{-l-}$ ) were analyzed by oneway ANOVA between subjects. Post hoc comparisons were made when required by Tukey's test after significant effects of treatment by one-way ANOVA. The data of physical state scale in depression model were analyzed by WilcoxonMann-Whitney nonparametric test. In all analysis, the null hypothesis was rejected at the 0.05 level.

\section{RESULTS}

\section{AQP4 Knockout Abolished the Anxiolytic and Antidepressive Effects of Fluoxetine}

To investigate whether AQP4 knockout altered the metabolism of fluoxetine, serum concentration, and hippocampal content of fluoxetine as well as its metabolite norfluoxetine (potent and selective serotonin uptake inhibitor as the parent drug) was measured at $0.25 \mathrm{~h}$ (distribution process), $5 \mathrm{~h}$ (half-life), and $12 \mathrm{~h}$ (elimination phase) after single fluoxetine $(10 \mathrm{mg} / \mathrm{kg}$, i.p) injection. As shown in Table 1 , at no time did the serum concentration or hippocampal content of fluoxetine and norfluoxetine differ significantly between $\mathrm{AQP} 4^{+1+}$ and $\mathrm{AQP} 4^{-l-}$ mice $(p>0.05, t$-test $)$.

Two-way ANOVA revealed a significant effect of fluoxetine $(\mathrm{F}(1,52)=4.763, p=0.034)$ on the feeding latency of NSF but no effects of genotype $(\mathrm{F}(1,52)=2.142, p=0.149)$ or interaction between genotype and fluoxetine $(\mathrm{F}(1,52)=2.512, p=0.119)$ under basal condition. Subsequent independent samples $t$-test indicated 4 -week fluoxetine treatment significantly decreased feeding latency of $\mathrm{AQP} 4^{+/+}$mice $(p=0.021)$ but had no effect on AQP4 ${ }^{-1-}$ mice $(p=0.653$; Figure 2a). Neither AQP4 knockout nor fluoxetine had significant effects on the immobility time in tail suspension test (two-way ANOVA: genotype $\mathrm{F}(1,52)=0.904, \quad p=0.346) ; \quad$ fluoxetine $\mathrm{F}(1,52)=2.339$, $p=0.132$; interaction: $\mathrm{F}(1,52)=0.683, p=0.412$; Figure $2 \mathrm{~b}$ ).

Chronic mild stress significantly degenerate the physical states during the first 3 weeks and lasted until the end of the 7-week CMS in stressed group of both genotypes (Figure 2c). The improvement of physical state by 4 -week administration of fluoxetine was more remarkable in $\mathrm{AQP} 4^{+1+}$ mice than in $\mathrm{AQP} 4^{-1-}$ mice $(p<0.001$, Figure 2c). Two-way ANOVA showed significant effect of treatment $(\mathrm{F}(2,79)=47.936, p<0.001)$ on body weight gain, but no effects of genotype $(\mathrm{F}(1,79)=1.225, p=0.272)$ or interaction between these two factors $(\mathrm{F}(2,79)=0.345$, $p=0.709)$. Subsequent one-way ANOVA showed a significant effect of treatment in $\mathrm{AQP} 4^{+/+}$mice $(\mathrm{F}(2,40)=31.631$, $p<0.001)$ and AQP4 ${ }^{-I-}$ mice $(\mathrm{F}(2,39)=18.082, p<0.001)$. Tukey's post hoc comparisons indicated that CMS procedure significantly inhibited body weight gain in both AQP4 ${ }^{+1+}$ and AQP4 ${ }^{-1-}$ mice $(p<0.001$, Figure $2 \mathrm{~d})$. Fluoxetine administration had no effect on body weight gain in both stressed AQP4 ${ }^{+1+}$ mice $(p=0.542)$ and $\mathrm{AQP} 4^{-1-}$ mice $(p=0.853$; Figure $2 \mathrm{~d})$. The despair-related behavior was

Table I Serum Concentration and Hippocampal Content of Fluoxetine and its Metabolite Norfluoxetine in $\mathrm{AQP}^{+/+}$and $\mathrm{AQP}^{-1-}$ Mice

\begin{tabular}{|c|c|c|c|c|}
\hline \multirow[b]{2}{*}{ Time } & \multicolumn{2}{|c|}{ Serum (ng/ml) } & \multicolumn{2}{|c|}{ Hippocampus (ng/g) } \\
\hline & $\mathrm{AQP4}^{+/+}$ & $\mathrm{AQP4}^{-1-}$ & $\mathrm{AQP4}^{+/+}$ & $\mathrm{AQP4}^{-1-}$ \\
\hline \multicolumn{5}{|l|}{$0.25 h$} \\
\hline $\mathrm{Flx}$ & $458.78 \pm 17.77$ & $439.91 \pm 22.01$ & $4369.67 \pm 244.79$ & $4499.64 \pm 259.23$ \\
\hline $\mathrm{Nflx}$ & < $189.37 \pm 31.02$ & $200.36 \pm 26.85$ & $868.02 \pm 135.30$ & $753.22 \pm 76.66$ \\
\hline \multicolumn{5}{|l|}{$5 h$} \\
\hline Flx & $337.61 \pm 12.40$ & $351.10 \pm 11.77$ & $|3| 6|.4| \pm 4|5.13|$ & $|46| 5.5| \pm 693.8|$ \\
\hline $\mathrm{Nflx}$ & < $643.82 \pm 117.43$ & $634.02 \pm 110.77$ & $53 \mid 4.84 \pm 285.50$ & $5250.66 \pm 470.75$ \\
\hline \multicolumn{5}{|l|}{$12 \mathrm{~h}$} \\
\hline Flx & $181.03 \pm 8.05$ & $163.44 \pm 5.65$ & $6580.85 \pm 233.99$ & $6104.13 \pm 219.70$ \\
\hline $\mathrm{Nflx}$ & $266.54 \pm 14.30$ & $257.03 \pm 11.68$ & $6952.01 \pm 351.78$ & $7077.37 \pm 771.24$ \\
\hline
\end{tabular}

AQP4, aquaporin-4; Flx, fluoxetine; Nflx, norfluoxetine.

Data represent the mean \pm SEM $(n=6)$ at different time following single

fluoxetine injection $(10 \mathrm{mg} / \mathrm{kg}$, i.p). 

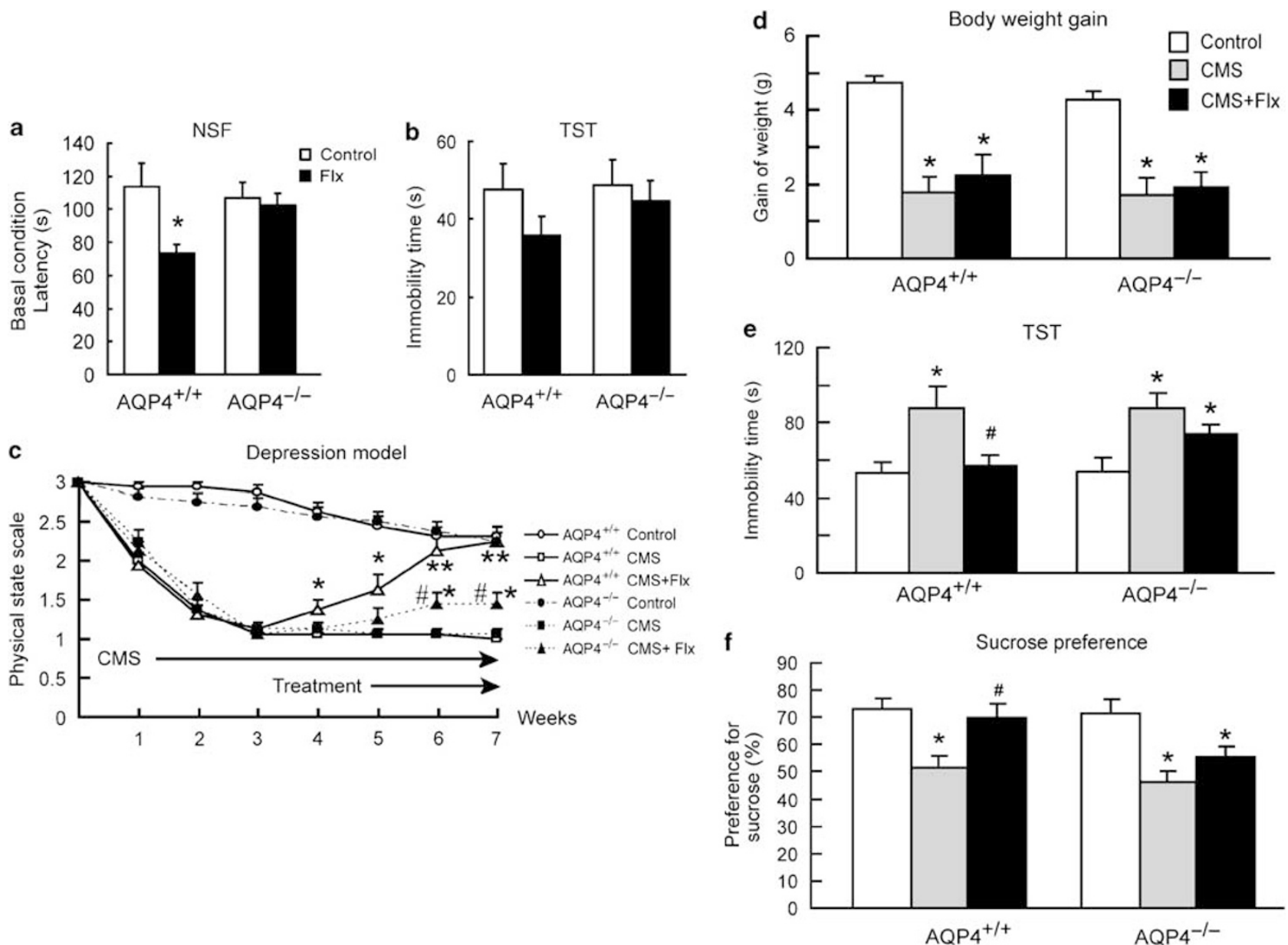

Figure 2 Aquaporin-4 (AQP4) knockout (KO) abolished the anxiolytic and antidepressive effects of fluoxetine (Flx). (a, b) Basal condition. (a) AQP4 KO abolished the anxiolytic effects of Flx in the novelty-suppressed feeding test ( $n=14$, ${ }^{*} p<0.05$ vs control group of the same genotype). (b) No significant difference of immobility time was found in tail suspension test (TST) after 4-week Flx administration in both genotypic mice $(n=14)$. (c, d, e, f) Depression model. (c) Effects of chronic mild stress (CMS) and chronic administration of Flx on the degradation of the physical state of the coat of AQP4 ${ }^{+/+}$- and AQP4 ${ }^{-1}$-stressed mice (Wilcoxon-Mann-Whitney nonparametric test, $n=14-16,{ }^{*} p<0.05$ and $* * p<0.01$ vs CMS group of the same genotype, ${ }^{\#} p<0.01$ vs AQP4 ${ }^{+/+}$CMS + Flx group). (d) Control mice showed significant increases on body weight gain whereas CMS inhibited body weight gain in both genotypes. Four-week Flx treatment had no effect on body weight gain in stressed mice $(n=14-15$, * $p<0.01$ vs control group of the same genotype). (e) CMS increased immobility time of both $\mathrm{AQP}^{+/+}$and AQP4 ${ }^{-1-}$ mice in the TST (*p $<0.05$ vs control group of the same genotype). Four-week Flx administration significantly decreased the immobility time in stressed $\mathrm{AQP} 4^{+/+}$mice $\left({ }^{\#} p<0.05\right.$ vs AQP4 ${ }^{+/+} \mathrm{CMS}$ group) but not in stressed $\mathrm{AQP} 4^{-/-}$ mice $(n=12)$. ( $f$ CMS decreased sucrose uptake in both genotypic mice $(* p<0.0$ I vs control group of the same genotype). Four-week Flx treatment restored sucrose preference in AQP4 ${ }^{+1+}$ mice $\left({ }^{\#} p<0.01\right.$ vs AQP4 ${ }^{+1+}$ CMS group), but not in AQP4 ${ }^{-1-}$ mice $(n=12)$.

measured with the TST. Two-way ANOVA revealed a significantly effect of treatment $(\mathrm{F}(2,66)=10.688$, $p<0.001)$ on the immobility times, but no effects of genotypes $(\mathrm{F}(1,66)=1.218, p=0.274)$ or interaction between these two factors $(\mathrm{F}(2,66)=1.148, p=0.323)$. Subsequent one-way ANOVA showed significant effects of treatment in $\mathrm{AQP4} 4^{+1+}$ mice $(\mathrm{F}(2,33)=6.086, p=0.006)$ and $\mathrm{AQP} 4^{-1-}$ mice $(\mathrm{F}(2,33)=5.698, p=0.007)$. Tukey's post hoc test showed that CMS significantly increased the immobility times in $\mathrm{AQP} 4^{+/+}$mice $(p=0.012)$ and $\mathrm{AQP} 4^{-1-}$ mice $(p=0.006$; Figure 2e). Fluoxetine administration reversed the CMS-induced increments of immobility time in AQP4 ${ }^{+1+}$ $(p=0.014)$ but not in $\mathrm{AQP} 4^{-1-}$ mice $(p=0.367$; Figure 2e). The anhedonia of mice was measured with sucrose preference test. Two-way ANOVA indicated genotype effect $(\mathrm{F}(1,66)=5.093, p=0.027)$, treatment effect $(\mathrm{F}(2,66)=15.588, p<0.001)$, but no interaction between these two factors $(\mathrm{F}(2,66)=1.512, p=0.228)$. Subsequent one-way ANOVA indicated a significant effect of treatment in both genotypic mice $\left(\mathrm{AQP} 4^{+/+}: \mathrm{F}(2,33)=8.563\right.$, $\left.p<0.001 ; \quad \mathrm{AQP4}{ }^{-l-}: \mathrm{F}(2,33)=8.539, \quad p<0.01\right)$. Tukey's comparison revealed that CMS procedure significantly inhibited the sucrose preference in both $\mathrm{AQP} 4^{+1+}$ mice $(p=0.002)$ and $\mathrm{AQP} 4^{-1-}$ mice $(p=0.001)$. However, fluoxetine only restored the CMS-induced decrement of sucrose preference in AQP4 ${ }^{+/+}$mice $(p=0.005)$ but not in $\mathrm{AQP} 4^{-l-}$ mice $(p=0.297)$ (Figure $\left.2 \mathrm{f}\right)$.

\section{AQP4 Knockout Suppressed Fluoxetine-Induced Enhancement of Neurogenesis in Adult Hippocampus}

The number of BrdU ${ }^{+}$cells in the SGZ $24 \mathrm{~h}$ after the last BrdU injection was used to evaluate the effects of 4-week fluoxetine treatment on cell proliferation. $\mathrm{BrdU}^{+}$cells 
exhibited fusiform or irregular phenotypes and were clustered or aggregated in the SGZ (Figure 3a). Under basal condition, two-way ANOVA indicated no effect of genotype $(\mathrm{F}(1,20)=2.077, p=0.165)$, but significant effect of fluoxetine $(\mathrm{F}(1,20)=28.943, p<0.001)$ and interaction between these two factors $(\mathrm{F}(1,20)=12.635, p=0.002)$. Subsequent independent samples $t$-test showed that fluoxetine significantly increased the number of $\mathrm{BrdU}^{+}$cell in $\mathrm{AQP} 4{ }^{+/+}$ mice $(p<0.001)$ but not in AQP4 $4^{-1-}$ mice $(p=0.229)$. As shown in Figure $3 b$, CMS significantly inhibited cell proliferation in the SGZ of both genotypes. Two-way ANOVA showed a significant effect of treatment on the number of $\mathrm{BrdU}^{+}$cells $(\mathrm{F}(2,30)=36.887, p<0.001)$, no effect of genotype $(\mathrm{F}(1,30)=2.683, p=0.112)$, and a significant interaction between treatment and genotype $(\mathrm{F}(2,30)=6.602, p=0.004)$. Subsequent one-way ANOVA indicated a significant effect of treatment in $\mathrm{AQP} 4^{+1+}$ mice $(\mathrm{F}(2,15)=21.841, p<0.001)$ and $\mathrm{AQP} 4{ }^{-1-}$ mice $(\mathrm{F}(2,15)=21.623, p<0.001)$. Post hoc comparisons revealed that CMS significantly inhibited cell proliferation in the SGZ of AQP4 ${ }^{+/+}$mice $(p<0.001)$ and AQP4 ${ }^{-/-}$mice $(p<0.001$; Figure $3 \mathrm{~b})$. Notably, 4 -week fluoxetine administration could reverse CMS-induced inhibition of cell proliferation in $\mathrm{AQP} 4^{+/+}(p<0.001)$ but not in AQP4 ${ }^{-1-}$ mice $(p=0.480$; Figure $3 b)$.

The numbers and phenotypes of dentate $\mathrm{BrdU}^{+}$cells were determined 4 weeks after the last BrdU administration, a time interval sufficient to allow for newly generated cells to migrate and differentiate (Ming and Song, 2005). At this time, the numbers of survival $\mathrm{BrdU}^{+}$cells among various groups were lower than those evaluated $24 \mathrm{~h}$ after the last BrdU injection under basal condition (two-way
ANOVA: genotype $\mathrm{F}(1,12)=1.655, p=0.223$; fluoxetine $\mathrm{F}(1,12)=14.897, \quad p=0.002$; interaction: $\mathrm{F}(1,12)=6.621$, $p=0.024$ ) and CMS-evoked depressive condition (two-way ANOVA: genotype $\mathrm{F}(1,18)=4.642, p=0.045$; treatment $\mathrm{F}(2,18)=21.048, \quad p<0.001$; interaction: $\mathrm{F}(2,18)=2.544$, $p=0.106$; Figure $4 \mathrm{a}, \mathrm{b})$. The survival rate of $\mathrm{BrdU}^{+}$cells referred to the percentage of the number of $\mathrm{BrdU}^{+}$cells between 28 days and 24 hours after last BrdU administration. The survival rates of various groups did not differ significantly under basal condition $\left(\mathrm{AQP} 4^{+/+}\right.$: control $46.41 \%$, fluoxetine $43.06 \%$; $\mathrm{AQP}^{-1-}$ : control $47.01 \%$, fluoxetine $46.98 \%$ ) and CMS-evoked depressive condition $\left(\mathrm{AQP} 4{ }^{+/+}\right.$: control $42.61 \%$, CMS $44.18 \%$, CMS + fluoxetine $40.89 \%$; $\mathrm{AQP}^{-I-}$ : control $40.60 \%$, CMS $42.73 \%$, CMS + fluoxetine $42.15 \%)$. These results indicate that AQP4 knockout failed to influence the survival of newborn cells in the SGZ. The phenotype of $\mathrm{BrdU}^{+}$cells was determined by double labeling of BrdU and neuronal marker neuronal nuclear antigen (NeuN) or astrocytic marker glial fibrillary acidic protein (GFAP; Figure 4c). No significant differences in the percentage of $\mathrm{NeuN}^{+} / \mathrm{BrdU}^{+}(\sim 75 \%)$ or $\mathrm{GFAP}^{+} /$ $\mathrm{BrdU}^{+}(\sim 10 \%)$ were observed among various groups under basal condition (two-way ANOVA; $\mathrm{NeuN}^{+}$/ $\mathrm{BrdU}^{+}$: genotype $\mathrm{F}(1,12)=0.069, p=0.798$; fluoxetine $\mathrm{F}(1,12)=0.392, \quad p=0.543$; interaction: $\mathrm{F}(1,12)=0.063$, $p=0.806 ; \quad \mathrm{GFAP}^{+} / \mathrm{BrdU}^{+}:$genotype $\mathrm{F}(1,12)=0.688$, $p=0.423$; fluoxetine $\mathrm{F}(1,12)=0.011, p=0.919$; interaction: $\mathrm{F}(1,12)=0.059, p=0.813$; Figure $4 \mathrm{~d})$. Similarly, no significant differences of $\mathrm{NeuN}^{+} / \mathrm{BrdU}^{+}$or $\mathrm{GFAP}^{+} / \mathrm{BrdU}^{+}$were found among various treatment group under CMS-evoked depressive condition (two-way ANOVA; $\mathrm{NeuN}^{+} / \mathrm{BrdU}^{+}$: genotype $\quad \mathrm{F}(1,18)=0.001, \quad p=0.991 ; \quad$ treatment: a
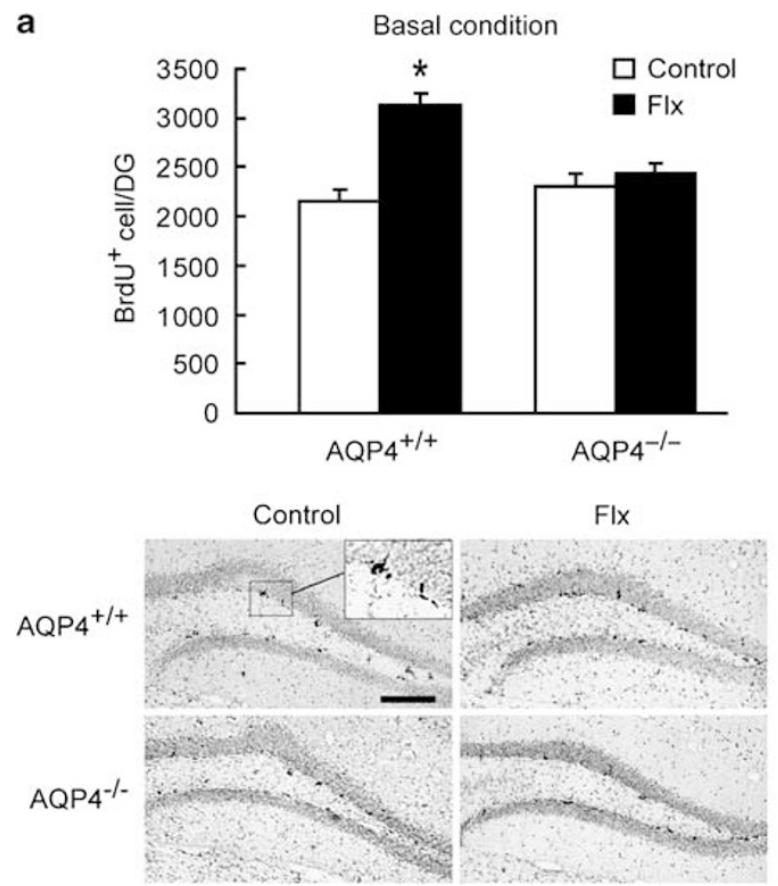

b
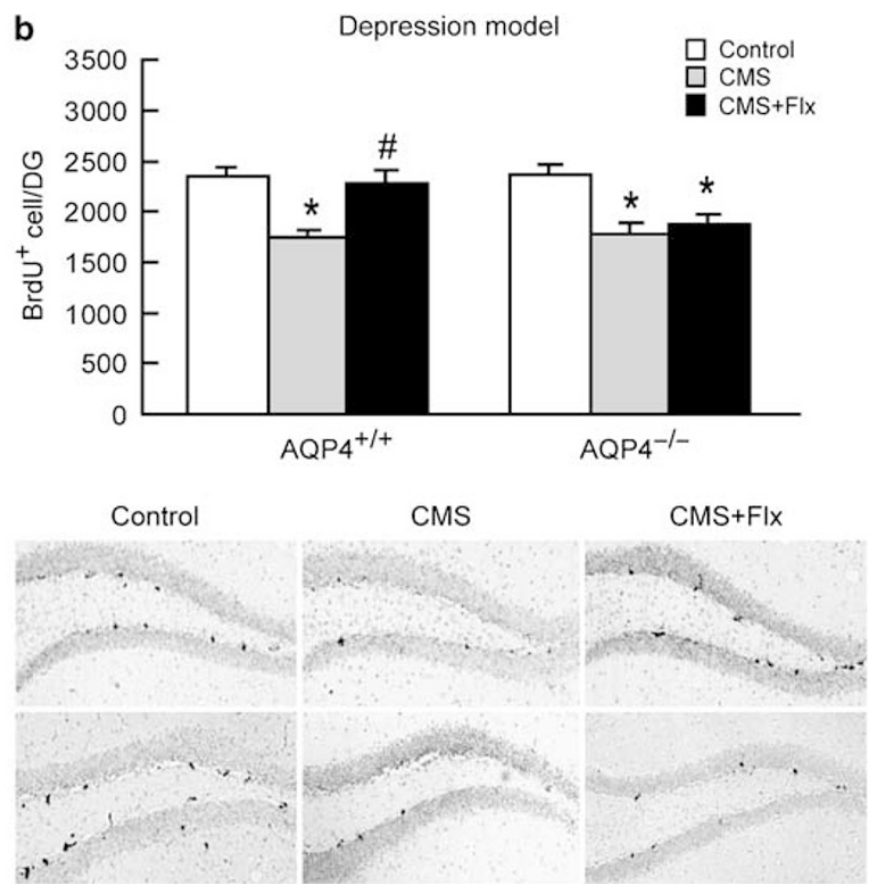

Figure 3 Aquaporin-4 (AQP4) knockout suppressed fluoxetine (Flx)-induced enhancement of cell proliferation in the subgranular zone (SGZ). (a) AQP4 knockout suppressed Flx-induced enhancement of cell proliferation in the SGZ under basal condition $\left(n=6\right.$, *p $<0.01$ vs AQP4 ${ }^{+/+}$control). (b) Chronic mild stress (CMS) decreased numbers of bromodeoxyuridine $(\mathrm{BrdU})^{+}$cells in the SGZ of both AQP4 ${ }^{+1+}$ and AQP4 ${ }^{-1-}$ mice $(n=6, * p<0.01$ vs control group of the same genotype). Four-week Flx treatment restored CMS-induced inhibition of cell proliferation in the SGZ of AQP4 ${ }^{+/+}$mice $\left({ }^{\#} p<0.01\right.$ vs $\mathrm{AQP4}^{+/+}$CMS group) but not in $\mathrm{AQP}^{-1-}$ mice. Scale bar $=200 \mu \mathrm{m}$. 
a

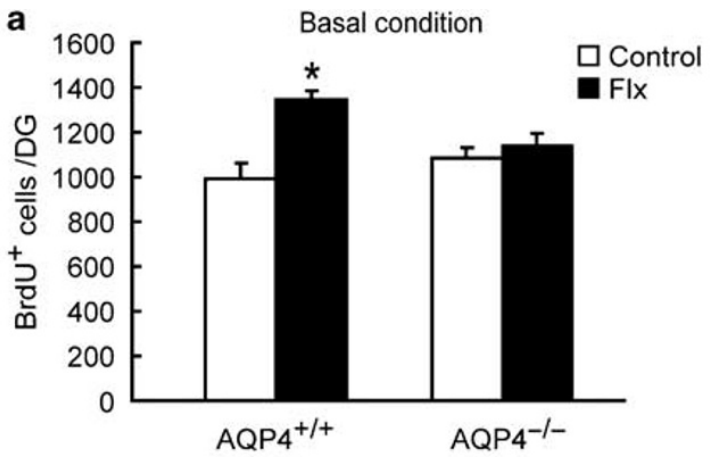

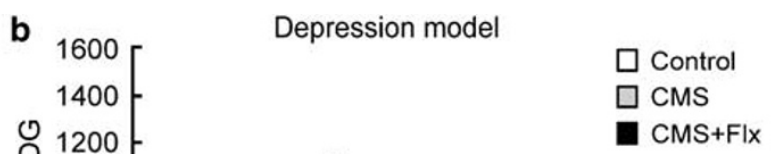
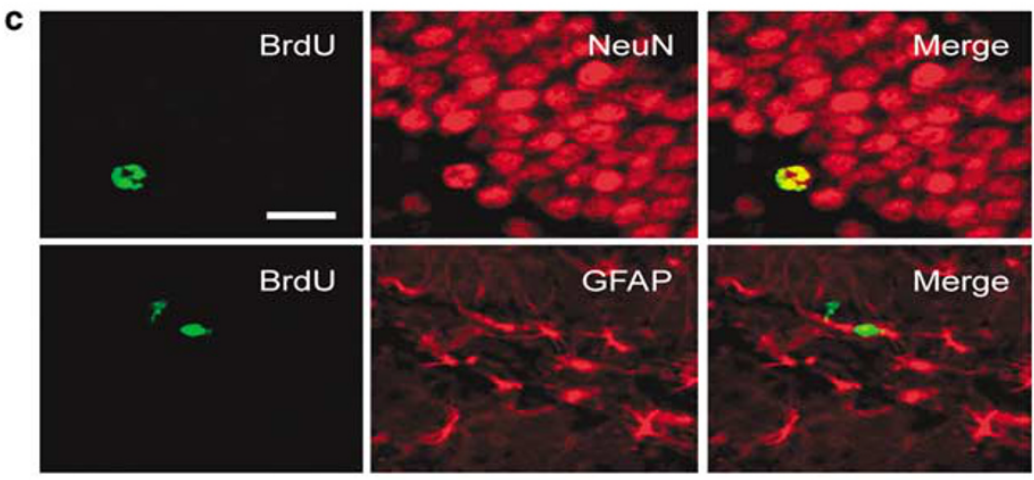

d

Basal condition

e

Depression modle
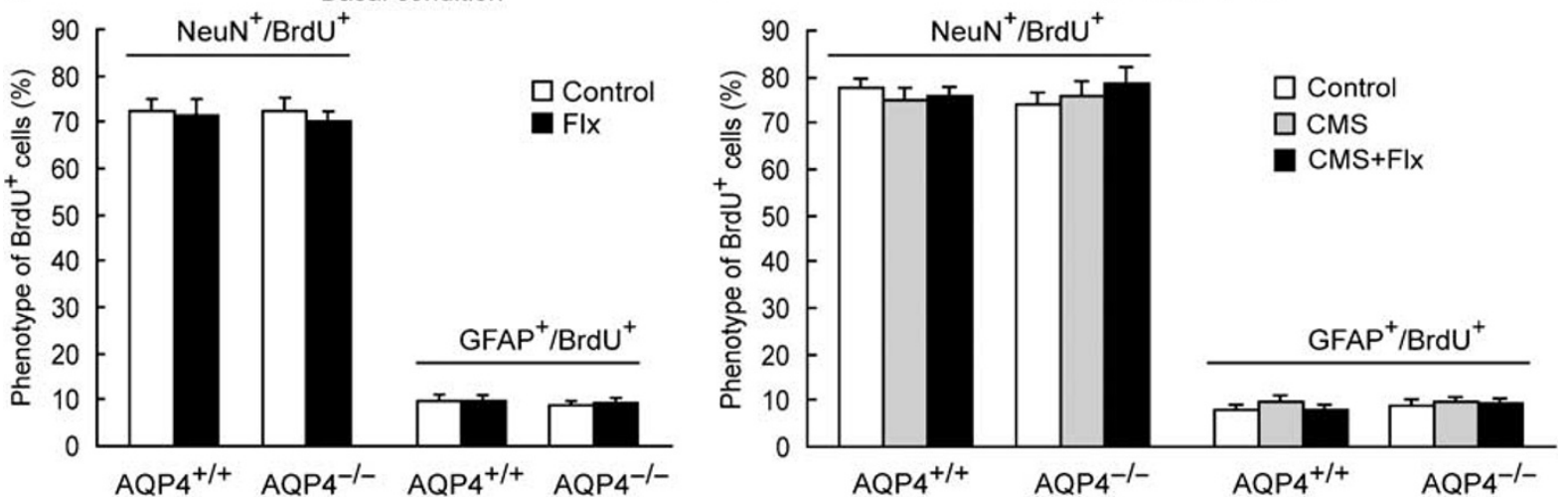

Figure 4 Fate and differentiation of bromodeoxyuridine $(\mathrm{BrdU})^{+}$cells in the dentate gyrus. (a) Under basal condition, 4-week fluoxetine (Flx) administration significantly increased the number of BrdU ${ }^{+}$cells 28 days after last BrdU injection in aquaporin-4 (AQP4) ${ }^{+/+}$but not in $\mathrm{AQP4}{ }^{-/-}$mice $\left(n=4\right.$, ${ }^{*} p<0.05$ vs control group of the same genotype, independent samples $t$-test). (b) The number of BrdU ${ }^{+}$cells in the subgranular zone (SGZ) of depression model mice 28 days after last BrdU administration $\left(n=4, * p<0.05\right.$ vs control group of the same genotype; ${ }^{\#} p<0.05$ vs AQP4 ${ }^{+/+}$chronic mild stress (CMS) group, Tukey's post hoc comparison). (c) Representative confocal microscopic images of BrdU (green) and neuronal nuclear antigen (NeuN) or glial fibrillary acidic protein (GFAP; red)-labeled cells in the dentate granule cell layer. Scale bar $=20 \mu \mathrm{m}$. (d, e) The percentages of NeuN ${ }^{+} / \mathrm{BrdU}^{+}$or GFAP ${ }^{+} / \mathrm{BrdU}^{+}$cell did not differ significantly among various groups under basal condition or CMS-evoked depressive condition $(n=4)$.

$\mathrm{F}(2,18)=0.283, \quad p=0.757 ; \quad$ interaction: $\mathrm{F}(2,18)=0.857$, $p=0.441 ; \mathrm{GFAP}^{+} / \mathrm{BrdU}^{+}$: genotype $\mathrm{F}(1,18)=0.811, p=0.38$ treatment: $\mathrm{F}(2,18)=1.152, p=0.338$, interaction: $\mathrm{F}(2,18)=0.395$, $p=0.679$; Figure $4 \mathrm{e})$.

\section{Fluoxetine Failed to Reverse CMS-Induced Hippocampal Volume Reduction in $\mathrm{AQP4}{ }^{-l-}$ Mice}

As hippocampal volume shrinkage was reported in chronic stress animal model (Alonso et al, 2004), we investigated the role of fluoxetine on hippocampal volume regulation in both $\mathrm{AQP}^{+/+}$and $\mathrm{AQP} 4^{-1-}$ mice under CMS-evoked depressive condition. Two-way ANOVA revealed a signifi- cant effect of treatment on the hippocampal volume $(\mathrm{F}(2,30)=11.183, \quad p=0.001)$ but not the genotype $(\mathrm{F}(1,30)=0.002, p=0.968)$ or interaction between treatment and genotype $(\mathrm{F}(2,30)=2.34, p=0.114)$. Subsequent one-way ANOVA indicated a significant effect of treatment on hippocampal volume in both AQP4 ${ }^{+1+}$ mice $(\mathrm{F}(2,15)=8.424, \quad p=0.004) \quad$ and $\mathrm{AQP}^{-1-}$ mice $(\mathrm{F}(2,15)=5.818, p=0.013)$. Tukey's post hoc test indicated that CMS procedure significantly decreased the hippocampal volume in both $\mathrm{AQP} 4^{+/+}$mice $(p=0.003)$ and AQP4 ${ }^{-/-}$ mice $(p=0.035)$. However, fluoxetine only reversed the CMS-induced shrinkage of hippocampal volume in $\mathrm{AQP} 4^{+/+}$mice $(p=0.032)$ but not in $\mathrm{AQP} 4^{-1-}$ mice 
$\left(p=0.949 ;\right.$ in $\mathrm{mm}^{3}, n=6 ; \mathrm{AQP}^{+l+}$ : control, $23.08 \pm 0.63$; CMS, $20.63 \pm 0.38$; CMS + fluoxetine, $22.18 \pm 0.27$; AQP $4^{-l-}$ : control, 23.72 \pm 0.53 ; CMS, $21.28 \pm 0.61$; CMS + fluoxetine, $20.76 \pm 0.89)$.

\section{AQP4 Knockout Suppressed Fluoxetine-Induced Enhancement of Hippocampal CREB and CaMKIV Phosphorylation}

The transcription factor CREB has been implicated in signaling pathways relevant to neurogenesis and depression. As transcriptional activity for CREB mainly depends on its phosphorylation at Ser133, hippocampal pCREB was measured by using an antibody directed against pCREB (Ser133). Two-way ANOVA showed significant effects of fluoxetine $(\mathrm{F}(1,12)=13.86, p=0.03)$ and genotype $(\mathrm{F}(1$, $12)=8.489, p=0.013$ ) on CREB phosphorylation, but no effect of interaction between fluoxetine and genotype $(\mathrm{F}(1,12,=1.284, p=0.279)$ under basal condition. Independent samples $t$-test showed that fluoxetine significantly increased the phosphorylation of CREB in AQP4 ${ }^{+/+}$mice $(p<0.001)$ but not in AQP4 ${ }^{-1-}$ mice $(p=0.396)$. We further investigated the effect of fluoxetine on hippocampal CREB phosphorylation in both $\mathrm{AQP} 4^{+/+}$and $\mathrm{AQP} 4^{-/-}$mice under CMS-evoked depressive condition. Two-way ANOVA revealed a significant effect of treatment $(\mathrm{F}(2,12)=13.82$, $p=0.001)$ but not effect of genotype $(\mathrm{F}(1,12)=4.167$, $p=0.064$ ), and a significant effect of interaction (genotype $\times$ treatment: $\mathrm{F}(2,12)=7.167, p=0.009)$. Subsequent oneway ANOVA revealed significant effects of treatment in both genotype mice (AQP4 ${ }^{+/+}: \mathrm{F}(1,6)=12.333, p=0.007$; AQP4 $\left.{ }^{-I-}: \mathrm{F}(1,6)=7.491, p=0.023\right)$. Tukey's post hoc tests showed that CMS procedure significantly inhibited hippocampal CREB phosphorylation in both AQP4 ${ }^{+1+}$ $(p=0.032)$ and AQP4 $4^{-l-}$ mice $(p=0.027)$. Fluoxetine reversed CMS-induced decrement of CREB phosphorylation in $\mathrm{AQP} 4^{+/+}$mice $(p=0.007)$ but not in $\mathrm{AQP} 4^{-/-}$mice $(p=0.880$; Figure $5 \mathrm{~b})$.

Aquaporin-4 knockout or fluoxetine failed to influence the activities of hippocampal PKA (two-way ANOVA, genotype $(1, \quad 12)=0.007, \quad p=0.936$; fluoxetine $(1,12)=0.014, \quad p=0.908$; $\quad$ interaction: $F(1,12)=0.02$, $p=0.889$; Figure $5 \mathrm{~d}$ ). Under CMS-evoked depressive condition, two-way ANOVA indicated treatment effect $(\mathrm{F}(2,30)=12.186, p<0.001)$, no genotype effect $(\mathrm{F}(1,30)=$ $0.012, p=0.912)$, and interaction between these two factors $(\mathrm{F}(2,30)=0.015, \quad p=0.985)$. Subsequent oneway ANOVA revealed significant effects of treatment in $\mathrm{AQP} 4^{+/+}(\mathrm{F}(2,15)=6.777, p=0.008)$ and $\mathrm{AQP} 4^{-l-}$ mice $(\mathrm{F}(2,15)=5.515, p=0.016)$. Tukey's post hoc test showed that CMS significantly inhibited hippocampal PKA activities in both $\mathrm{AQP} 4^{+/+}$mice $(p=0.012)$ and $\mathrm{AQP} 4^{-/-}$mice $(p=0.027)$. Fluoxetine restored the CMS-induced inhibition of PKA activities in both genotypes (Figure $5 \mathrm{~d}$ ).

Four-week fluoxetine administration failed to influence the activities of hippocampal PKC under basal condition. However, AQP4 knockout significant increased hippocampal PKC activity (two-way ANOVA: genotype $\mathrm{F}(1,12)=17.386, \quad p=0.001 ; \quad$ fluoxetine $\mathrm{F}(1,12)=0.911$, $p=0.359 ; \quad$ interaction: $\quad \mathrm{F}(1,12)=0.088, \quad p=0.772$; Figure 5e). Consistently, the hippocampal PKC activities also increased in $\mathrm{AQP} 4^{-1-}$ mice under CMS-evoked depressive condition. However, neither CMS nor fluoxetine altered PKC activity in both mouse genotypes (Figure 5f). Thus, two-way ANOVA showed a significant effect of genotype $(\mathrm{F}(1,18)=19.592, p<0.001)$, but no effect of treatment $(\mathrm{F}(2,18)=0.048, p=0.954)$ or interaction between genotype and treatment $(\mathrm{F}(2,18)=0.137, p=0.873)$.

The phosphorylation of extracellular signal-regulated kinases (ERK1/2) was not altered by 4 -week fluoxetine administration in both genotypes under basal condition (two-way ANOVA; genotype $\mathrm{F}(1,8)=0.022$, $p=0.887$; fluoxetine $\mathrm{F}(1,8)=0.013, p=0.913$; interaction: $\mathrm{F}(1,8)=0.192, p=0.673$; Figure $5 \mathrm{~g})$. However, the phosphorylation of ERK1/2 was affected by CMS and fluoxetine in both genotypes (Figure $5 \mathrm{~h}$ ). Two-way ANOVA revealed a significant effect of treatment $(\mathrm{F}(2,12)=17.301, p<0.001)$ on ERK1/2 phosphorylation, but no effect of genotype $(\mathrm{F}(1,12)=0.191, p=0.67)$ or interaction between genotype and treatment $(\mathrm{F}(2,12)=0.569, p=0.58)$. Post hoc tests showed that CMS procedure significantly inhibited hippocampal ERK1/2 phosphorylation in both $\mathrm{AQP} 4^{+/+}$mice $(p=0.042)$ and AQP4 ${ }^{-1-}$ mice $(p=0.036)$. Fluoxetine reversed the CMS-induced decrement of ERK1/2 phosphorylation in both genotypes ( $p<0.05$; Figure $5 \mathrm{~h}$ ).

As shown in Figure 5i, fluoxetine increased the phosphorylation of CaMKIV in $\mathrm{AQP} 4^{+/+}$mice but not in AQP4 ${ }^{-l-}$ mice under basal condition. Two-way ANOVA showed significant effects of fluoxetine $(\mathrm{F}(1,12)=11.947$, $p=0.005)$ and genotype $(\mathrm{F}(1,12)=5.31, p=0.04)$ on hippocampal CaMKIV phosphorylation, but no interaction between these two factors $(\mathrm{F}(1,12)=2.602, p=0.133)$.

Figure 5 Aquaporin-4 (AQP4) knockout inhibited fluoxetine (Flx)-induced cyclic AMP-responsive element binding protein (CREB) and calcium/ calmodulin-dependent protein kinase IV (CaMKIV) phosphorylation. (a) Four-week Flx treatment significantly increased hippocampal CREB phosphorylation in $\mathrm{AQP4}{ }^{+/+}$but not in $\mathrm{AQP4}{ }^{-1-}$ mice $\left(n=4, * p<0.05 \mathrm{vs} \mathrm{AQP4}{ }^{+/+}\right.$control). (b) Flx reversed chronic mild stress (CMS)-induced reduction of hippocampal CREB phosphorylation in AQP4 ${ }^{+/+}$but not in AQP4 ${ }^{-1-}$ mice $(n=3, * p<0.05$ vs control group of the same genotype; ${ }^{\#} p<0.01$ vs AQP4 $\left.{ }^{+1+} \mathrm{CMS}\right)$. (c) Under basal conditions, AQP4 knockout or Flx did not alter hippocampal protein kinase $A(P K A)$ activity $(n=4)$. (d) In depression model, Flx reversed the CMS-induced inhibition of hippocampal PKA activity in both genotypic mice $(n=6$, * $p<0.05$ vs control group of the same genotype; ${ }^{\#} p<0.05$ vs CMS group of the same genotype). (e) AQP4 knockout enhanced hippocampal PKC activity, whereas Flx did not alter the PKC activity under basal condition ( $n=4$, *** $<0.0$ I for significant main effect of genotype). (f) CMS or Flx did not influence the PKC activity in depression model ( $n=4,{ }^{*} * 0.0$ I for significant main effect of genotype). (g) AQP4 knockout or Flx had no effect on hippocampal extracellular signal-regulated kinases (ERKI/2) phosphorylation under basal condition $(n=3)$. (h) In depression model, Flx restored CMS-induced decrement of hippocampal ERKI/2 phosphorylation in both genotypic mice ( $n=3,{ }^{*} p<0.05$ vs control group of the same genotype; ${ }^{\#} p<0.05$ vs CMS group of the same genotype). (i) Under basal condition, 4-week Flx administration increased hippocampal CaMKIV phosphorylation in AQP4 ${ }^{+1+}$ but not in AQP4 ${ }^{-1-}$ mice $(n=4$, * $p<0.01$ vs $\mathrm{AQP4}{ }^{+/+}$control). (j) Flx reversed CMS-induced inhibition of hippocampal CaMKIV phosphorylation in AQP4 ${ }^{+/+}$mice but not in AQP4 ${ }^{-l-}$ mice $(n=4$, ${ }^{*} p<0.05$ vs control group of the same genotype, ${ }^{\#} p<0.01$ vs AQP4 ${ }^{+}+$CMS group). 
Independent samples $t$-test indicated that fluoxetine significantly increased the phosphorylation of CaMKIV in $\mathrm{AQP} 4^{+/+}$mice $(p=0.002)$ but not in $\mathrm{AQP} 4^{-l-}$ mice $(p=0.213)$. Further, we investigated hippocampal CaMKIV phosphorylation under CMS-evoked depressive condition. Two-way ANOVA revealed significant effect of treatment
$(\mathrm{F}(2,18)=17.884, \quad p<0.001)$, genotype $(\mathrm{F}(1,18)=11.395$, $p=0.003)$, and interaction of these two factors $(\mathrm{F}(2,18)=8.327, p=0.003)$ on CaMKIV phosphorylation. Subsequent one-way ANOVA revealed significant effects of treatment in both $\mathrm{AQP} 4^{+/+}$mice $(\mathrm{F}(2,9)=22.164$, $p<0.001)$ and AQP4 ${ }^{-I-}$ mice $(\mathrm{F}(2,9)=8.253, p=0.009)$.
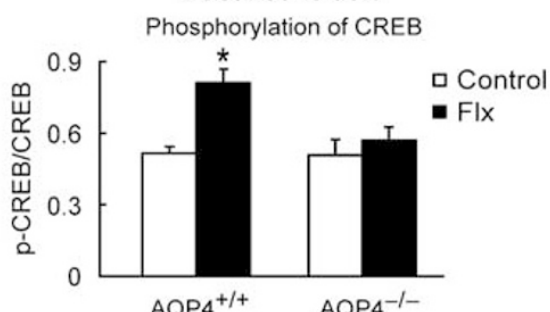

p-CREB

$\mathrm{AQP}^{+/+} \quad \mathrm{AQP}^{-1-}$ CREB

C

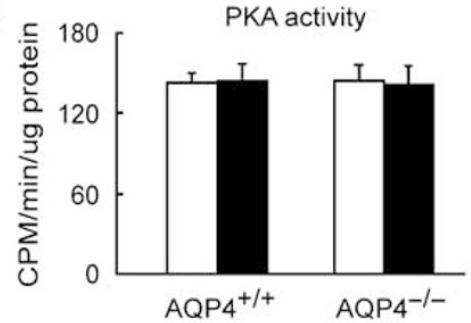

e

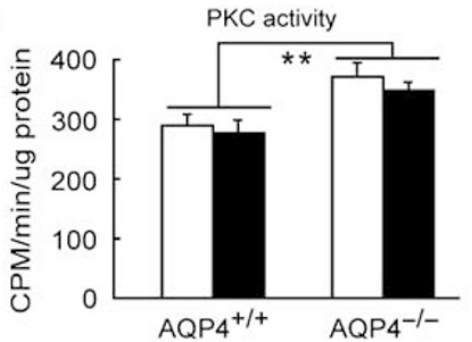

g

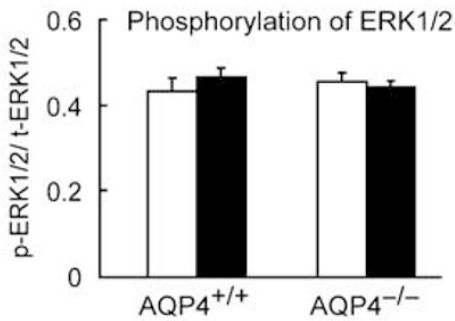

p-ERK1/2

t-ERK1/2

i

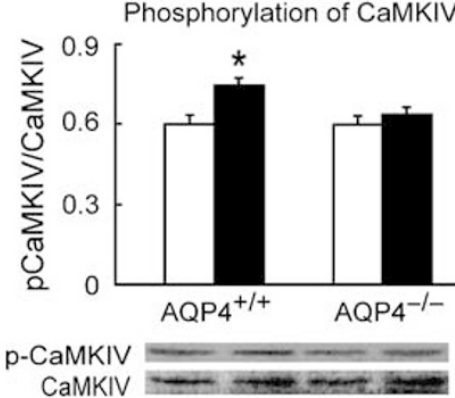

b

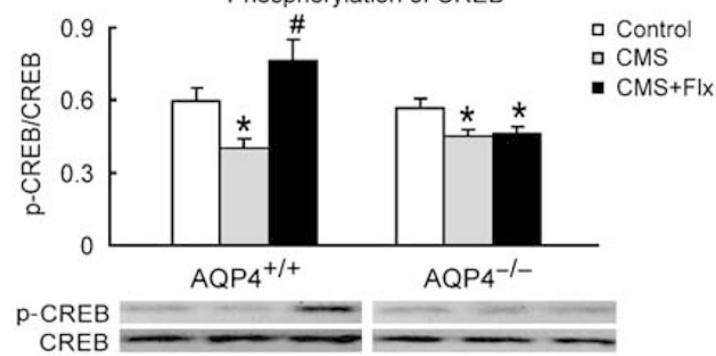

d

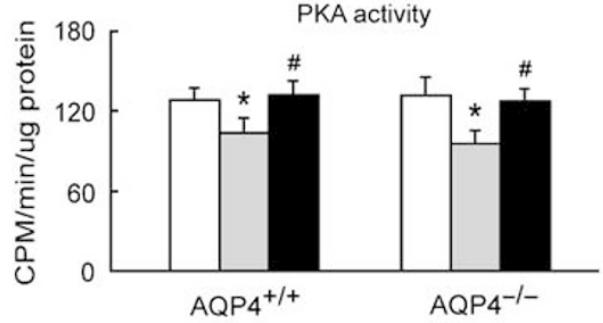

f

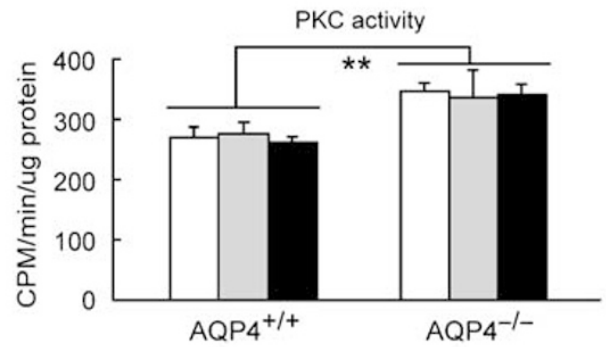

h

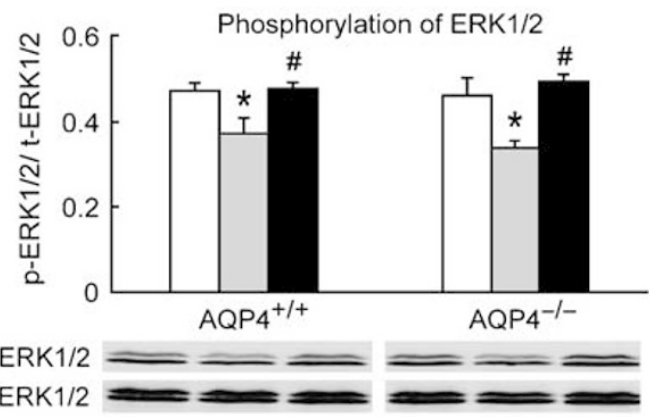

j

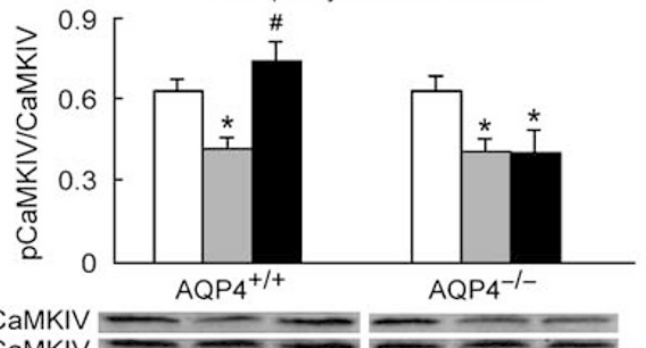


Tukey's post hoc comparison indicated that CMS significantly inhibited CaMKIV phosphorylation in the hippocampus of $\mathrm{AQP} 4^{+/+}$mice $(p=0.002)$ and $\mathrm{AQP} 4^{-/-}$mice $(p=0.014)$. Notably, 4 -week fluoxetine administration could restore CMS-induced decrement of hippocampal CaMKIV phosphorylation in $\mathrm{AQP} 4^{+/+}$mice $(p<0.001)$ but not in AQP4 ${ }^{-1-}$ mice $(p=0.967$; Figure $5 \mathrm{j})$.

\section{Chronic Fluoxetine Treatment Inhibited CMS-Induced Upregulation of AQP4 Expression in the Hippocampus}

Under basal conditions, 4-week fluoxetine treatment resulted in a minor but insignificant increase $(114 \%$ of control) in AQP4 expression in the hippocampus $(n=3, t$ test, $p=0.16$; Figure 6a). CMS significantly increased expression of AQP4 (177\% of control, $p=0.001$; one-way ANOVA, $F(2,9)=15.409, p=0.001)$, which was reversed by 4 -week fluoxetine administration ( $p=0.006$ vs CMS group, Figure 6b).

\section{AQP4 Knockout Inhibited Proliferation of ANSCs and Abolished the Pro-Proliferative Effect of Fluoxetine In Vitro}

In floating culture medium, ANSCs derived from adult hippocampus formed neurospheres (Figure 7a) and expressed AQP4 (Figure 7b), and nestin (Figure 7c). To investigate whether AQP4 knockout affected fluoxetineinduced enhancement of proliferation in vitro, ANSCs were incubated with $0.1,1 \mu \mathrm{M}$ fluoxetine, and $1 \mu \mathrm{Ci} / \mathrm{ml}\left[{ }^{3} \mathrm{H}\right]-$ thymidine for $48 \mathrm{~h}$. As indicated by two-way ANOVA analysis, AQP4 knockout significantly inhibited the proliferation of ANSCs in vitro (genotype $\mathrm{F}(1,12)=80.012$, $p<0.001$; treatment: $\mathrm{F}(2,12)=4.098, p=0.044$; interaction: $\mathrm{F}(2,12)=3.073, \quad p=0.084)$. Tukey's post hoc analysis showed that 0.1 and $1 \mu \mathrm{M}$ fluoxetine significantly promoted the proliferation of AQP $4^{+/+}$ANSC by $31 \%(p=0.008)$ and $22 \%(p=0.038)$, respectively. However, no pro-proliferative effect of fluoxetine was found in AQP4 ${ }^{-/-}$ANSCs (one-way ANOVA, $F(2,6)=1.867, p=0.234$, Figure $7 d)$.

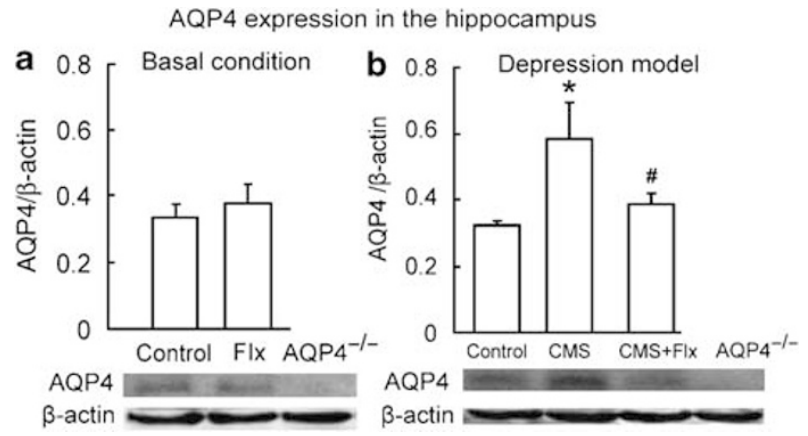

Figure 6 Aquaporin-4 (AQP4) expression in hippocampus following 4-week fluoxetine (Flx) administration. (a) Four-week Flx administration did not affect hippocampal AQP4 expression under basal condition $(n=3)$. (b) Chronic mild stress (CMS) significantly increased AQP4 expression in the hippocampus, which was reversed by 4-week Flx treatment $(n=4$, ${ }^{*} p<0.0$ I vs control; ${ }^{\#} p<0.0$ I vs CMS).

\section{DISCUSSION}

In the present study, we first showed that AQP4 knockout suppressed fluoxetine-induced enhancement of adult hippocampal neurogenesis in mice. Meanwhile, the anxiolytic and antidepressive actions of fluoxetine disappeared following AQP4 knockout. We next showed that AQP4 knockout suppressed fluoxetine-induced hippocampal CREB phosphorylation by inhibiting CaMKIV pathway rather than PKA, PKC, and ERK1/2 pathways. Furthermore, the CMS procedure significantly increased hippocampal AQP4 expression, which was reversed by 4-week fluoxetine treatment. Finally, in vitro study using cultured ANSCs from adult hippocampus demonstrated that AQP4 knockout not only significantly inhibited the primary proliferation, but also eliminated the pro-proliferative effect of fluoxetine. These findings suggest that AQP4 can regulate fluoxetineinduced enhancement of adult hippocampal neurogenesis and in turn mediate the antidepressive action of fluoxetine.

During the past decade, studies have shown that impaired neurogenesis in the hippocampus of adults may play a role in the pathogenesis of depression (Gould et al, 1997; Pittenger and Duman, 2008). Psychosocial stress reduces neurogenesis in rodents, whereas chronic treatment with antidepressants enhances neurogenesis and reverses the effects of stress (Alonso et al, 2004; Jayatissa et al, 2006). The effects of stress and antidepressant treatment on neurogenesis in the hippocampus parallel behavioral changes in animal models (Santarelli et al, 2003). The observation that neurogenesis parallels the actions of antidepressant drugs may lead to novel strategies for treatment of depression. However, the development of new treatments for depression based on hippocampal neurogenesis requires identification of the mechanisms responsible for adult neurogenesis and elucidation of the pivotal components of the pathophysiology of depression. In the present study, AQP4 knockout eliminated fluoxetineinduced enhancement of adult neurogenesis both in vivo and in vitro. Thus, AQP4 is required for fluoxetine-induced enhancement of adult hippocampal neurogenesis. Notably, CMS significantly increased expression of hippocampal $\mathrm{AQP} 4$. In general, brain water homeostasis disequilibrium is associated with increased AQP4 expression in astroglia (Arima et al, 2003; Badaut et al, 2002; Vizuete et al, 1999), and excessive AQP4 may be detrimental and promote edema (Papadopoulos et al, 2004a, b; Papadopoulos and Verkman, 2005; Quick and Cipolla, 2005). Therefore, AQP4 may be involved in the CMS-induced depression by regulating brain water homeostasis.

Aquaporin-4 knockout impaired proliferation of ANSCs in vitro, suggesting that AQP4 could modulate adult hippocampal neurogenesis by regulating the proliferation of stem cell directly. However, no significant differences were found in basal neurogenesis in the hippocampus between adult $\mathrm{AQP} 4^{-1-}$ and $\mathrm{AQP} 4^{+1+}$ mice. The apparently discordant findings between in vivo and in vitro investigations could be attributed to alterations in the extracellular microenvironment, which may compensate for inhibition of proliferation of ANSCs in AQP4 ${ }^{-I-}$ mice. For instance, serotonin, a monoamine neurotransmitter that promotes neurogenesis in the hippocampus of adults (Banasr et al, 2004; Brezun and Daszuta, 1999; Djavadian, 2004), was 

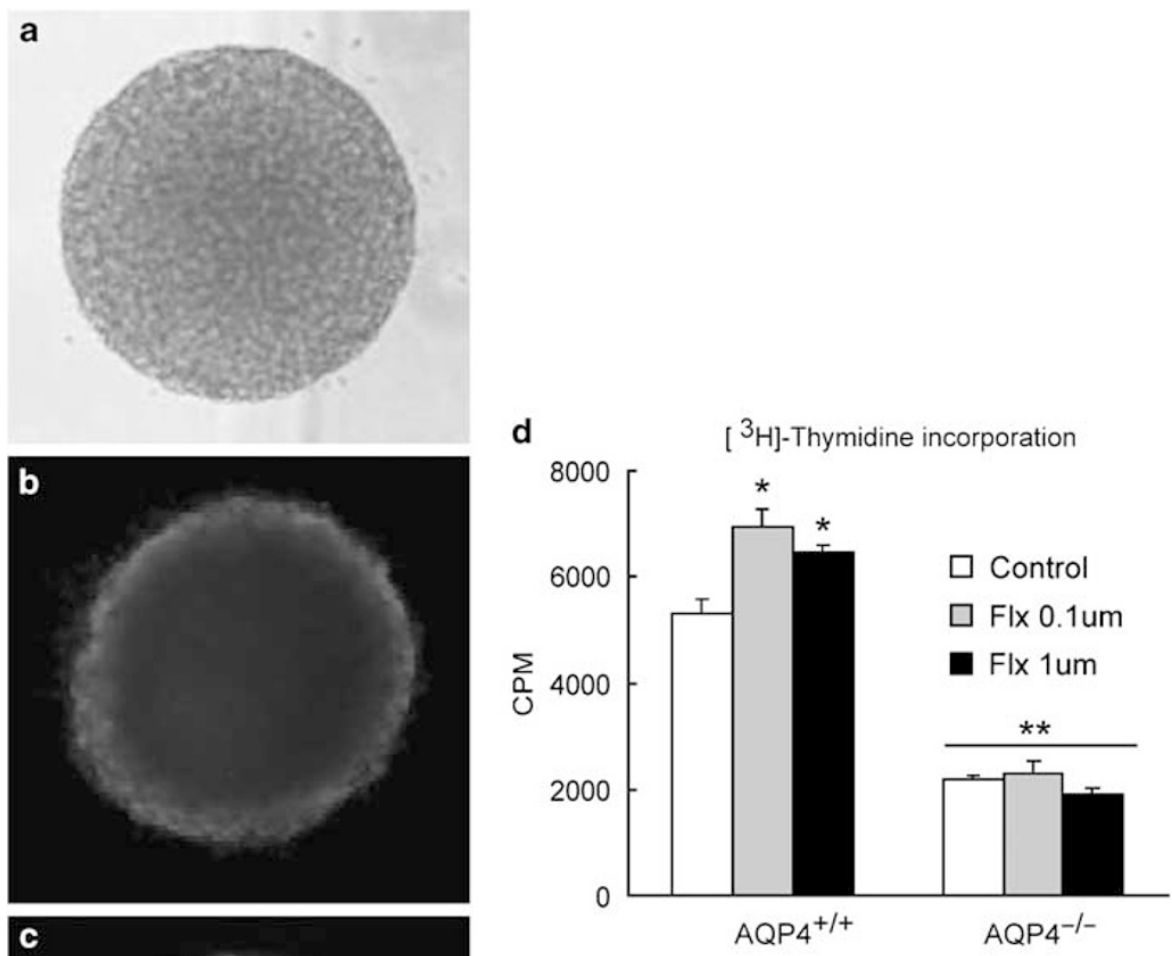
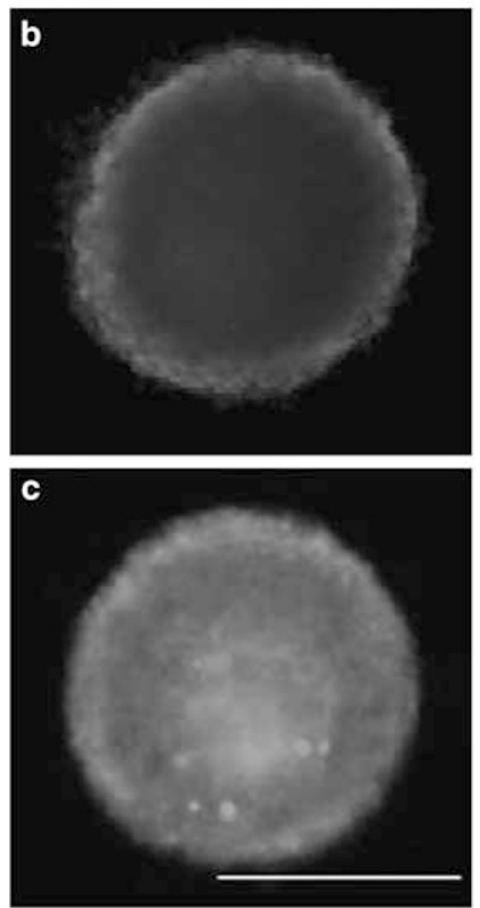

Figure 7 Proliferation assay of neural stem cells by $\left[{ }^{3} \mathrm{H}\right]$ thymidine incorporation. (a) Neural stem cells isolated from adult hippocampus generated neurospheres. Scale bar $=200 \mu \mathrm{m}$. Neurospheres expressed aquaporin-4 (AQP4; b) and nestin (c). (d) AQP4 knockout significantly inhibited the proliferation of adult neural stem cells (ANSCs) in vitro (** $<<0.01$ for significant main effect of genotype). Fluoxetine (Flx, 0.1 and I $\mu M)$ significantly enhanced proliferation of AQP4 ${ }^{+/+}$ANSC, but had no effect on AQP4 ${ }^{-1-}$ ANSCs $\left(n=3,{ }^{*} p<0.05\right.$ vs AQP4 ${ }^{+/+}$control).

significantly increased in various brain regions in $\mathrm{AQP} 4^{-1-}$ mice (Fan et al, 2005). Therefore, increased levels of serotonin in vivo may counteract the inhibition of proliferation of ANSCs in $\mathrm{AQP} 4^{-1-}$ mice via activation of different serotonin receptors, such as 5-HT1A, 5-HT2A, and/or 5-HT2C.

Fluoxetine, a selective serotonin reuptake inhibitor, can enhance neurogenesis both in vivo and in vitro (Malberg and Duman, 2003; Malberg et al, 2000; Manev et al, 2001). Our previous studies have demonstrated that AQP4 regulates the serotoninergic neurotransmission in different regions of the adult brain (Ding et al, 2007; Fan et al, 2005). Therefore, we presume that AQP4 might involve the therapeutic effects of fluoxetine. In the present study, in vivo experiments revealed AQP4 knockout abolished fluoxetine-induced enhancement of neurogenesis in the hippocampus and behavioral improvements in adult mice under both basal and CMS-induced depressive conditions. These results are consistent with the findings that AQP4 knockout abolished the pro-proliferative effects of fluox- etine in cultured ANSCs. Our study also reveals that AQP4 knockout failed to alter metabolism of fluoxetine in brain. Therefore, AQP4 is necessary for the therapeutic actions of fluoxetine, and this function of AQP4 is likely mediated by regulating adult hippocampal neurogenesis. Notably, 4week fluoxetine treatment could reverse CMS-induced upregulation of AQP4 in the hippocampus. Although blockade of AQP4 (and thus cell permeability to water) is predicted to reduce brain swelling in neurologic diseases (Amiry-Moghaddam et al, 2003; Manley et al, 2000; Papadopoulos and Verkman, 2005), no selective AQP4 channel blockers are currently available. Furthermore, AQP4 channel blockers may negatively affect hearing (Li and Verkman, 2001) and vision (Li et al, 2002) and increase brain swelling when vasogenic brain edema predominates, such as brain tumor or the late stages of stroke (Papadopoulos et al, 2004a,b). As increased expression of AQP4 accounts for the majority of excess water in the brain, perhaps inhibitors of AQP4 upregulation may be better drugs than AQP4 channel blockers (Papadopoulos and 
Verkman, 2005). Our findings suggest fluoxetine may be a potential mediator for AQP4 expression.

Neuroimaging studies in humans reveal that the hippocampal volume undergoes reduction in major depression (Bremner et al, 2000; Colla et al, 2007; Sheline et al, 1999). Consistent with these findings, hippocampal volume was decreased in chronic stress paradigms and various animal models of depression, although it could be reversed by chronic antidepressants treatment (Alonso et al, 2004; Czeh et al, 2001; van der Hart et al, 2002). Our study showed that CMS significantly decreased the hippocampal volume of both $\mathrm{AQP} 4^{+1+}$ and $\mathrm{AQP} 4^{-1-}$ mice. However, 4-week fluoxetine treatment could reverse the CMS-induced hippocampal volume reduction in $\mathrm{AQP} 4^{+/+}$mice but not in $\mathrm{AQP}^{-/-}$mice. These results indicate that AQP4 participates in the regulation of hippocampal volume during the period of CMS and fluoxetine treatment. The present study showed that the hippocampal volume was parallel to the neurogenesis among various groups of $\mathrm{AQP}^{+/+}$and $\mathrm{AQP}{ }^{-\prime-}$ mice, suggesting that $\mathrm{AQP} 4$ may mediate hippocampal volume regulation at least partially by regulating hippocampal cell proliferation.

Cyclic AMP-responsive element binding protein (CREB) has been implicated in signaling pathways related to the pathogenesis and therapy of depression (Carlezon et al, 2005; Zhu et al, 2004). CMS inhibited CREB phosphorylation in the hippocampus of both $\mathrm{AQP} 4^{+/+}$and $\mathrm{AQP} 4^{-/-}$ mice. Three main kinases, PKA, CaMKIV, and ERK1/2, are involved in regulation of CREB phosphorylation in response to fluoxetine (Carlezon et al, 2005; Tiraboschi et al, 2004). The present study demonstrated CMS significantly inhibited activation of these kinases in both $\mathrm{AQP} 4^{+/+}$and $\mathrm{AQP} 4^{-/-}$ mice. Thus, PKA, CaMKIV, and ERK1/2 are involved in CMS-induced depression in both genotypes of mice. Fourweek fluoxetine treatment reversed CMS-induced inhibition of PKA, ERK1/2, and CaMKIV activities, and CREB phosphorylation in the hippocampus of $\mathrm{AQP} 4^{+/+}$mice. The same treatment also reversed CMS-induced inhibition of PKA activity and ERK1/2 phosphorylation but failed to reverse inhibition of CaMKIV and CREB phosphorylation in the hippocampus of $\mathrm{AQP} 4^{-l-}$ mice. Compared with $\mathrm{AQP} 4^{+/+}$mice, the findings in $\mathrm{AQP} 4^{-l-}$ mice suggest that PKA and ERK1/2 signaling cascades are not involved in the differences of CREB phosphorylation following fluoxetine treatment. Three calcium/CaM-dependent kinases (CaMK I, II, and IV) have been shown to phosphorylate CREB in response to intracellular calcium (Hook and Means, 2001). CaMKIV has a pronounced nuclear localization and plays a primary role in neuronal activity-dependent phosphorylation of CREB (Lonze and Ginty, 2002). CREB phosphorylation is mainly blocked by CaMK inhibitors but not by other kinases (including PKA, PKC, and MAPK; Bito et al, 1996). Moreover, CaMKIV knockout greatly attenuates both basal and activity-dependent phosphorylation of CREB in the hippocampus (Ho et al, 2000). Therefore, our findings suggest AQP4 may regulate the antidepressive action of fluoxetine via the CaMKIV-CREB pathway.

It is well established that PKA and PKC can regulate the water permeability of AQP4 by reversible protein phosphorylation in a short-term way. Briefly, PKC phosphorylation at $\operatorname{Ser}^{180}$ in the AQP4 protein acts to reduce water influx through the channel (Han et al, 1998; Zelenina et al,
2002), and PKA phosphorylation at $\operatorname{Ser}^{111}$ is speculated to increase permeability of AQP4 (Gunnarson et al, 2004). Moreover, AQP4 is downregulated by stimulation of the PKC pathway (Tang et al, 2007; Yamamoto et al, 2001). In the present study, hippocampal PKC activity was increased by AQP4 knockout, which reveals an interaction between the regulations of PKC signaling and AQP4.

In conclusion, our findings demonstrate for the first time that AQP4 is required for the antidepressive action of fluoxetine via regulating adult hippocampal neurogenesis.

\section{ACKNOWLEDGEMENTS}

We appreciate Dr Kevin Ellsworth (Barrow Neurological Institute, Phoenix, AZ 85013, USA) for his kindly suggestion during the paper writing and Dr Juncheng Dai (Department of Epidemiology and Biostatistics, Nanjing Medical University) for his guidance on statistic analysis. These studies were supported by grants from the National Natural Science Foundation of China (nos. 30625038, 30701017, and 30700216) and the National Key Basic Research Program of China (nos. 2009CB521906 and 2005CB500706).

\section{DISCLOSURE/CONFLICT OF INTEREST}

The authors declare that, except for income received from their primary employer, no financial support or compensation has been received from any individual or corporate entity over the past 3 years for research or professional service and there are no personal financial holdings that could be perceived as constituting a potential conflict of interest.

\section{REFERENCES}

Alonso R, Griebel G, Pavone G, Stemmelin J, Le Fur G, Soubrie P (2004). Blockade of CRF(1) or V(1b) receptors reverses stressinduced suppression of neurogenesis in a mouse model of depression. Mol Psychiatry 9: 278-286.

Amiry-Moghaddam M, Otsuka T, Hurn PD, Traystman RJ, Haug FM, Froehner SC et al (2003). An alpha-syntrophin-dependent pool of AQP4 in astroglial end-feet confers bidirectional water flow between blood and brain. Proc Natl Acad Sci USA 100: 2106-2111.

Arima H, Yamamoto N, Sobue K, Umenishi F, Tada T, Katsuya H et al (2003). Hyperosmolar mannitol simulates expression of aquaporins 4 and 9 through a p38 mitogen-activated protein kinase-dependent pathway in rat astrocytes. J Biol Chem 278: 44525-44534.

Badaut J, Lasbennes F, Magistretti PJ, Regli L (2002). Aquaporins in brain: distribution, physiology, and pathophysiology. J Cereb Blood Flow Metab 22: 367-378.

Banasr M, Hery M, Printemps R, Daszuta A (2004). Serotonininduced increases in adult cell proliferation and neurogenesis are mediated through different and common 5-HT receptor subtypes in the dentate gyrus and the subventricular zone. Neuropsychopharmacology 29: 450-460.

Bilkei-Gorzo A, Racz I, Michel K, Zimmer A (2002). Diminished anxiety- and depression-related behaviors in mice with selective deletion of the Tac1 gene. J Neurosci 22: 10046-10052.

Bito H, Deisseroth K, Tsien RW (1996). CREB phosphorylation and dephosphorylation: a $\mathrm{Ca}^{2+}$ - and stimulus duration-dependent switch for hippocampal gene expression. Cell 87: 1203-1214. 
Bodnoff SR, Suranyi-Cadotte B, Aitken DH, Quirion R, Meaney MJ (1988). The effects of chronic antidepressant treatment in an animal model of anxiety. Psychopharmacology (Berl) 95: 298-302.

Bonfanti L, Peretto P (2007). Radial glial origin of the adult neural stem cells in the subventricular zone. Prog Neurobiol 83: 24-36.

Bremner JD, Narayan M, Anderson ER, Staib LH, Miller HL, Charney DS (2000). Hippocampal volume reduction in major depression. Am J Psychiatry 157: 115-118.

Brezun JM, Daszuta A (1999). Depletion in serotonin decreases neurogenesis in the dentate gyrus and the subventricular zone of adult rats. Neuroscience 89: 999-1002.

Carlezon Jr WA, Duman RS, Nestler EJ (2005). The many faces of CREB. Trends Neurosci 28: 436-445.

Cavazzin C, Ferrari D, Facchetti F, Russignan A, Vescovi AL, La Porta CA et al (2006). Unique expression and localization of aquaporin-4 and aquaporin-9 in murine and human neural stem cells and in their glial progeny. Glia 53: 167-181.

Colla M, Kronenberg G, Deuschle M, Meichel K, Hagen T, Bohrer $M$ et al (2007). Hippocampal volume reduction and HPA-system activity in major depression. J Psychiatr Res 41: 553-560.

Cotter D, Mackay D, Landau S, Kerwin R, Everall I (2001a). Reduced glial cell density and neuronal size in the anterior cingulate cortex in major depressive disorder. Arch Gen Psychiatry 58: 545-553.

Cotter DR, Pariante CM, Everall IP (2001b). Glial cell abnormalities in major psychiatric disorders: the evidence and implications. Brain Res Bull 55: 585-595.

Cryan JF, Mombereau C, Vassout A (2005). The tail suspension test as a model for assessing antidepressant activity: review of pharmacological and genetic studies in mice. Neurosci Biobehav Rev 29: 571-625.

Czeh B, Michaelis T, Watanabe T, Frahm J, de Biurrun G, van Kampen $M$ et al (2001). Stress-induced changes in cerebral metabolites, hippocampal volume, and cell proliferation are prevented by antidepressant treatment with tianeptine. Proc Natl Acad Sci USA 98: 12796-12801.

Czeh B, Simon M, Schmelting B, Hiemke C, Fuchs E (2006). Astroglial plasticity in the hippocampus is affected by chronic psychosocial stress and concomitant fluoxetine treatment. Neuropsychopharmacology 31: 1616-1626.

Davidson JR, Meoni P, Haudiquet V, Cantillon M, Hackett D (2002). Achieving remission with venlafaxine and fluoxetine in major depression: its relationship to anxiety symptoms. Depress Anxiety 16: 4-13.

Ding JH, Sha LL, Chang J, Zhou XQ, Fan Y, Hu G (2007). Alterations of striatal neurotransmitter release in aquaporin-4 deficient mice: an in vivo microdialysis study. Neurosci Lett 422: $175-180$

Djavadian RL (2004). Serotonin and neurogenesis in the hippocampal dentate gyrus of adult mammals. Acta Neurobiol Exp (Wars) 64: 189-200.

Doetsch F (2003). A niche for adult neural stem cells. Curr Opin Genet Dev 13: 543-550.

El Yacoubi M, Bouali S, Popa D, Naudon L, Leroux-Nicollet I, Hamon $M$ et al (2003). Behavioral, neurochemical, and electrophysiological characterization of a genetic mouse model of depression. Proc Natl Acad Sci USA 100: 6227-6232.

Fan Y, Kong H, Shi X, Sun X, Ding J, Wu J et al (2008). Hypersensitivity of aquaporin 4-deficient mice to 1-methyl-4phenyl-1,2,3,6-tetrahydropyrindine and astrocytic modulation. Neurobiol Aging 29: 1226-1263.

Fan Y, Zhang J, Sun XL, Gao L, Zeng XN, Ding JH et al (2005). Sexand region-specific alterations of basal amino acid and monoamine metabolism in the brain of aquaporin- 4 knockout mice. J Neurosci Res 82: 458-464.

Gould E, McEwen BS, Tanapat P, Galea LA, Fuchs E (1997). Neurogenesis in the dentate gyrus of the adult tree shrew is regulated by psychosocial stress and NMDA receptor activation. J Neurosci 17: 2492-2498.

Grippo AJ, Beltz TG, Weiss RM, Johnson AK (2006). The effects of chronic fluoxetine treatment on chronic mild stress-induced cardiovascular changes and anhedonia. Biol Psychiatry 59: 309-316.

Gunnarson E, Zelenina M, Aperia A (2004). Regulation of brain aquaporins. Neuroscience 129: 947-955.

Han Z, Wax MB, Patil RV (1998). Regulation of aquaporin-4 water channels by phorbol ester-dependent protein phosphorylation. J Biol Chem 273: 6001-6004.

Ho N, Liauw JA, Blaeser F, Wei F, Hanissian S, Muglia LM et al (2000). Impaired synaptic plasticity and cAMP response element-binding protein activation in $\mathrm{Ca}^{2+} /$ calmodulin-dependent protein kinase type IV/Gr-deficient mice. J Neurosci 20: 6459-6472.

Hook SS, Means AR (2001). $\mathrm{Ca}^{2+} / \mathrm{CaM}$-dependent kinases: from activation to function. Annu Rev Pharmacol Toxicol 41: 471-505.

Jacobs BL, Praag H, Gage FH (2000). Adult brain neurogenesis and psychiatry: a novel theory of depression. Mol Psychiatry 5: 262-269.

Jayatissa MN, Bisgaard C, Tingstrom A, Papp M, Wiborg O (2006). Hippocampal cytogenesis correlates to escitalopram-mediated recovery in a chronic mild stress rat model of depression. Neuropsychopharmacology 31: 2395-2404.

Jordan JD, Ma DK, Ming GL, Song H (2007). Cellular niches for endogenous neural stem cells in the adult brain. CNS Neurol Disord Drug Targets 6: 336-341.

Li J, Patil RV, Verkman AS (2002). Mildly abnormal retinal function in transgenic mice without Muller cell aquaporin-4 water channels. Invest Ophthalmol Vis Sci 43: 573-579.

Li J, Verkman AS (2001). Impaired hearing in mice lacking aquaporin-4 water channels. J Biol Chem 276: 31233-31237.

Lie DC, Song H, Colamarino SA, Ming GL, Gage FH (2004). Neurogenesis in the adult brain: new strategies for central nervous system diseases. Annu Rev Pharmacol Toxicol 44: $399-421$.

Lim DA, Alvarez-Buylla A (1999). Interaction between astrocytes and adult subventricular zone precursors stimulates neurogenesis. Proc Natl Acad Sci USA 96: 7526-7531.

Lonze BE, Ginty DD (2002). Function and regulation of CREB family transcription factors in the nervous system. Neuron 35: 605-623.

Ma T, Yang B, Gillespie A, Carlson EJ, Epstein CJ, Verkman AS (1997). Generation and phenotype of a transgenic knockout mouse lacking the mercurial-insensitive water channel aquaporin-4. J Clin Invest 100: 957-962.

Malberg JE, Duman RS (2003). Cell proliferation in adult hippocampus is decreased by inescapable stress: reversal by fluoxetine treatment. Neuropsychopharmacology 28: $1562-1571$

Malberg JE, Eisch AJ, Nestler EJ, Duman RS (2000). Chronic antidepressant treatment increases neurogenesis in adult rat hippocampus. J Neurosci 20: 9104-9110.

Manev H, Uz T, Smalheiser NR, Manev R (2001). Antidepressants alter cell proliferation in the adult brain in vivo and in neural cultures in vitro. Eur J Pharmacol 411: 67-70.

Manley GT, Fujimura M, Ma T, Noshita N, Filiz F, Bollen AW et al (2000). Aquaporin-4 deletion in mice reduces brain edema after acute water intoxication and ischemic stroke. Nat Med 6: 159-163.

Ming GL, Song H (2005). Adult neurogenesis in the mammalian central nervous system. Annu Rev Neurosci 28: 223-250.

Muller MB, Lucassen PJ, Yassouridis A, Hoogendijk WJ, Holsboer F, Swaab DF (2001). Neither major depression nor glucocorticoid treatment affects the cellular integrity of the human hippocampus. Eur J Neurosci 14: 16031612 . 
Padmawar P, Yao X, Bloch O, Manley GT, Verkman AS (2005). $\mathrm{K}^{+}$ waves in brain cortex visualized using a long-wavelength $\mathrm{K}^{+}$sensing fluorescent indicator. Nat Methods 2: 825-827.

Papadopoulos MC, Manley GT, Krishna S, Verkman AS (2004a). Aquaporin-4 facilitates reabsorption of excess fluid in vasogenic brain edema. FASEB J 18: 1291-1293.

Papadopoulos MC, Saadoun S, Binder DK, Manley GT, Krishna S, Verkman AS (2004b). Molecular mechanisms of brain tumor edema. Neuroscience 129: 1011-1020.

Papadopoulos MC, Verkman AS (2005). Aquaporin-4 gene disruption in mice reduces brain swelling and mortality in pneumococcal meningitis. J Biol Chem 280: 13906-13912.

Pittenger C, Duman RS (2008). Stress, depression, and neuroplasticity: a convergence of mechanisms. Neuropsychopharmacology 33: 88-109.

Quick AM, Cipolla MJ (2005). Pregnancy-induced up-regulation of aquaporin-4 protein in brain and its role in eclampsia. FASEB J 19: $170-175$.

Roy M, David N, Cueva M, Giorgetti M (2007). A study of the involvement of melanin-concentrating hormone receptor 1 (MCHR1) in murine models of depression. Biol Psychiatry 61: 174-180.

Sairanen M, Lucas G, Ernfors P, Castren M, Castren E (2005). Brain-derived neurotrophic factor and antidepressant drugs have different but coordinated effects on neuronal turnover, proliferation, and survival in the adult dentate gyrus. J Neurosci 25: 1089-1094.

Santarelli L, Saxe M, Gross C, Surget A, Battaglia F, Dulawa S et al (2003). Requirement of hippocampal neurogenesis for the behavioral effects of antidepressants. Science 301: 805-809.

Sheline YI, Gado MH, Kraemer HC (2003). Untreated depression and hippocampal volume loss. Am J Psychiatry 160: 1516-1518.

Sheline YI, Sanghavi M, Mintun MA, Gado MH (1999). Depression duration but not age predicts hippocampal volume loss in medically healthy women with recurrent major depression. J Neurosci 19: 5034-5043.

Song H, Stevens CF, Gage FH (2002). Astroglia induce neurogenesis from adult neural stem cells. Nature 417: 39-44.

Strekalova T, Gorenkova N, Schunk E, Dolgov O, Bartsch D (2006). Selective effects of citalopram in a mouse model of stress-induced anhedonia with a control for chronic stress. Behav Pharmacol 17: 271-287.

Tang Y, Cai D, Chen Y (2007). Thrombin inhibits aquaporin 4 expression through protein kinase C-dependent pathway in cultured astrocytes. J Mol Neurosci 31: 83-93.

Tiraboschi E, Tardito D, Kasahara J, Moraschi S, Pruneri P, Gennarelli $\mathrm{M}$ et al (2004). Selective phosphorylation of nuclear CREB by fluoxetine is linked to activation of CaM kinase IV and MAP kinase cascades. Neuropsychopharmacology 29: 1831-1840. van der Hart MG, Czeh B, de Biurrun G, Michaelis T, Watanabe T, Natt $\mathrm{O}$ et al (2002). Substance $\mathrm{P}$ receptor antagonist and clomipramine prevent stress-induced alterations in cerebral metabolites, cytogenesis in the dentate gyrus and hippocampal volume. Mol Psychiatry 7: 933-941.

Verkman AS (2005). More than just water channels: unexpected cellular roles of aquaporins. J Cell Sci 118: 3225-3232.

Vizuete ML, Venero JL, Vargas C, Ilundáin AA, Echevarría M, Machado A et al (1999). Differential upregulation of aquaporin-4 mRNA expression in reactive astrocytes after brain injury: potential role in brain edema. Neurobiol Dis 6: 245-258.

Volterra A, Meldolesi J (2005). Astrocytes, from brain glue to communication elements: the revolution continues. Nat Rev Neurosci 6: 626-640.

Yamamoto N, Sobue K, Miyachi T, Inagaki M, Miura Y, Katsuya $\mathrm{H}$ et al (2001). Differential regulation of aquaporin expression in astrocytes by protein kinase C. Brain Res Mol Brain Res 95: 110-116.

Zelenina M, Zelenin S, Bondar AA, Brismar H, Aperia A (2002). Water permeability of aquaporin- 4 is decreased by protein kinase $\mathrm{C}$ and dopamine. Am J Physiol Renal Physiol 283: F309-F318.

Zeng XN, Sun XL, Gao L, Fan Y, Ding JH, Hu G (2007). Aquaporin4 deficiency down-regulates glutamate uptake and GLT-1 expression in astrocytes. Mol Cell Neurosci 34: 34-39.

Zhou J, Kong H, Hua X, Xiao M, Ding J, Hu G (2008). Altered blood-brain barrier integrity in adult aquaporin-4 knockout mice. Neuroreport 19: 1-5.

Zhu DY, Lau L, Liu SH, Wei JS, Lu YM (2004). Activation of cAMPresponse-element-binding protein (CREB) after focal cerebral ischemia stimulates neurogenesis in the adult dentate gyrus. Proc Natl Acad Sci USA 101: 9453-9457.

Supplementary Information accompanies the paper on the Neuropsychopharmacology website (http://www.nature.com/npp) 